\title{
Kinetic control concept for the diffusion processes of paracetamol active molecules across affinity polymer membranes from acidic solutions
}

\author{
Sanae Tarhouchi* ${ }^{*}$, Rkia Louafy, El Houssine El Atmani and Miloudi Hlaïbi
}

\begin{abstract}
Background: Paracetamol compound remains the most used pharmaceutical as an analgesic and antipyretic for pain and fever, often identified in aquatic environments. The elimination of this compound from wastewater is one of the critical operations carried out by advanced industries. Our work objective was to assess studies based on membrane processes by using two membranes, polymer inclusion membrane and grafted polymer membrane containing gluconic acid as an extractive agent for extracting and recovering paracetamol compound from aqueous solutions.

Result: The elaborated membrane characterizations were assessed using Fourier-transform infrared spectroscopy (FTIR) and scanning electron microscopy (SEM). Kinetic and thermodynamic models have been applied to determine the values of macroscopic $\left(\boldsymbol{P}\right.$ and $\left.\boldsymbol{J}_{\mathbf{0}}\right)$, microscopic $\left(\boldsymbol{D}^{*}\right.$ and $\left.\boldsymbol{K}_{\text {ass }}\right)$, activation and thermodynamic parameters $\left(\boldsymbol{E}_{\boldsymbol{a}}, \boldsymbol{\Delta} \boldsymbol{H}^{\#}\right.$, $\Delta \boldsymbol{S}^{\#}, \boldsymbol{\Delta} \boldsymbol{H}^{\#}{ }_{\text {diss }}$, and $\left.\boldsymbol{\Delta} \boldsymbol{H}^{\#}{ }_{t h}\right)$. All results showed that the PVA-GA was more performant than its counterpart GPM-GA, with apparent diffusion coefficient values $\left(10^{7} D^{*}\right)$ of 41.807 and $31.211 \mathrm{~cm}^{2} \mathrm{~s}^{-1}$ respectively, at $T=308 \mathrm{~K}$. In addition, the extraction process for these membranes was more efficient at $\mathrm{pH}=1$. The relatively low values of activation energy ( $\boldsymbol{E} \boldsymbol{a})$, activation association enthalpy $\left(\boldsymbol{\Delta} \boldsymbol{H}_{\text {ass }}^{*}\right.$ ), and activation dissociation enthalpy $\left(\boldsymbol{\Delta} \boldsymbol{H}^{\boldsymbol{*}}\right.$ diss $)$ have indicated a kinetic control for the oriented processes studied across the adopted membranes much more than the energetic counterpart.
\end{abstract}

Conclusion: The results presented for the quantification of oriented membrane process ensured clean, sustainable, and environmentally friendly methods for the extraction and recovery of paracetamol molecule as a high-value substance.

Keywords: Facilitated extraction, Affinity membranes, Permeability, Apparent diffusion coefficient, Association constant, Kinetic, And energetic controls

\section{Introduction}

In the last few decades, increasing attention has been paid to pharmaceutical industries that generate liquid wastes containing several pollutants and toxic substances

\footnotetext{
*Correspondence: sanae.tarhouchi@gmail.com

Laboratoire Génie des Matériaux pour Environnement et Valorisation

(GeMEV), Faculté des Sciences Ain Chock, Hasssan II University

of Casablanca (UH2C), PB 5366, Maârif, Maroc
}

[1-4]. These pollutants induce undesirable effects on the ecosystem and can potentially cause unexpected consequences and unintended effects on living organisms [5-8]. Consequently, treating these wastes becomes a major environmental issue for modern pharmaceutical industries and scientific research institutions. New technologies for the extraction, separation, and elimination of organic or inorganic substances and the recovery of several value-added molecules for evaluating these releases 
must be developed [9-12] to minimize and reduce the formation rate of toxic products [13].

Paracetamol is the raw material of many pharmaceutical products. Due to commercial and medical uses, modern industries use special methods to develop this active ingredient, which is not effectively removed by conventional methods during wastewater treatment. Thus, this pharmaceutical compound remains in municipal effluents, and different paracetamol concentrations have been detected in various parts of the world $[14,15]$. Long-term exposure to drugs containing this active pharmaceutical ingredient can cause severe damage to humans and other animals [16-19]. Therefore, its recovery and extraction from industrial liquid waste is the need of the hour.

In recent years, various membrane processes have been reported for various applications [20-22] (such as removal, purification, recovery, and extraction of organic compounds present in liquid wastewater). Membranebased technology has become critical and has attracted much attention as a valuable technology for many industries due to the distinctive capability of selective and efficient extraction of target species (e.g., ions/small molecules). It is an environmentally friendly alternative that considerably reduces the volume of used chemical products, and minimal energy is consumed during the process. These methods are successfully applied in several fields, such as environment, energy, health, water treatment, cosmetic, food, chemical, and pharmaceutical industries. Depending on their structure, composition, and morphology, a wide range of membranes (including organic polymer membranes) can be developed for use in different fields. These favorable properties and functionalities exhibit clear and important advantages compared to other separation and extraction techniques such as resin separation, liquid-liquid extraction (ELL), solid-phase extraction (EPS), and chromatography [2327]. These properties help in determining the selectivity parameters in particular.

In general, the extraction mechanism through a membrane is based on facilitated diffusion. These oriented membranes that promote facilitated extraction are now the subject of several studies. Facilitated extraction membranes employ chemicals (hereafter denoted extractive agent) to specifically and reversibly react with the target spices to form (Substrate-Extractive agent) complexes, then transport the complexes from the feed phase to the receiving phase allowing the regeneration of the substrate via reverse reactions. The separation efficiency of the facilitated extraction through the polymer membranes is principally governed by reaction kinetics at membrane/aqueous solution interfaces, together with the extraction rate of the complexes (Substrate-Extractive agent) through the membrane matrix. According to the extraction agent mobility and physicochemical properties of the facilitated extraction membrane, an extraction mechanism based on the successive jump of the substrate via a semi-mobile and fixed extractive agent has been proposed [28]. The studied membranes polymer inclusion membranes (PIMs), and grafted polymer membranes (GPMs), as two major types of facilitated extraction membranes, have attracted much attention in fundamental studies and practical applications [29-32]. Due to the simple preparation steps, stability, better mechanical properties, good chemical resistance, better mechanical properties, and particularly stable integration of the extractive agent into the polymer support, special attention is paid to PIMs and GPMs [33-36].

This study highlights the development of a clean and sustainable treatment process in the pharmaceutical industry. Accordingly, in our laboratory, experiments related to the facilitated extraction process of paracetamol, which is used here as a model drug to evaluate the extraction capabilities of the membrane process, were carried out to extract the active substances from the liquid solution. Our challenge was to determine the proper and selective extractive agent and examine its effectiveness in developing a stable and efficient membrane for extracting paracetamol. We also aimed to evaluate the parameters to achieve high recovery, high throughput, and low consumption time. This extraction process was performed using PIM and GPM containing gluconic acid (GA) as the extractive agent. The prepared membranes were characterized by two techniques: (i) Fourier-transform infrared spectroscopy and (ii) scanning electron microscopy (SEM) techniques to confirm the presence of the extractive agent in the polymeric support. The developed membranes were used to perform oriented processes for facilitated extraction and to recover paracetamol substrates under the influence of the initial substrate concentration, acidity, and temperature of the medium. The dynamics of mass transfer and the effect of the different factors on the extracting the paracetamol substrate were discussed. The kinetically determining step, which controls the rate of paracetamol extraction when PIMs and GPMs are used, has been elucidated by analyzing the kinetic data.

\section{Methods/experimental}

\section{Chemicals and reagents}

Paracetamol was purchased from ICN Biomedicals. All polymers, polyvinyl alcohol (PVA) $\left(\mathrm{Mw}=72,000 \mathrm{~g} \mathrm{~mol}^{-1}\right)$, polysulfone (PSU) $\left(\mathrm{Mw}=35,000 \mathrm{~g} \mathrm{~mol}^{-1}\right)$, polyvinyl-pyrrolidone (PVP) $\left(\mathrm{Mw}=45,000 \mathrm{~g} \mathrm{~mol}^{-1}\right), \mathrm{GA}(\mathrm{Mw}=218$, $2 \mathrm{~g} \mathrm{~mol}^{-1}$ ), and the solvent $N, N$-dimethylformamide (DMF, 99.8\%) and dimethylsulfoxide (DMSO'99.8\%), are commercial products (Aldrich, Fluka). Double distilled water 
was used in all experiments. The $\mathrm{pH}$ of aqueous solutions was adjusted with an analytical grade solution of hydrochloric acid $(\mathrm{HCl})$ from Sigma.

\section{Instruments and apparatus}

The acidities of the aqueous solutions (feed phase and receiving phase) were measured using a $\mathrm{pH}$ meter (HANNA Instruments HI 8519N). A UV-visible spectrophotometer (Rayleigh. U.V.-2601) was used, to determine the paracetamol concentration $\left(C_{R}\right)$ in the receiving phase. Two infrared spectrophotometers, AVATAR 360 FTIR ESP and JASCO model 4600 were used to plot the FTIR spectra to identify the presence of extractive agents in the polymer matrix. Similarly, the scanning electron microscopy (SEM) technique was used to produce different micrographs and study the morphology and porosity of the developed membranes by (ZEISS EVO40 EP) and (JEOL NeoScope JCM-500). Their thicknesses were measured using an electronic micrometer (Mitutoyo).

\section{Membrane preparation}

To conduct the oriented processes of the facilitated extraction of paracetamol, we have prepared two types of polymer membranes PIM and GPM, based on polyvinyl alcohol and polysulfone as polymer support with the same extractive agent (GA).

The adopted GPM was developed according to the following experimental protocol [37]: a $3 \mathrm{~g}$ of polysulfone polymer dissolved in $13 \mathrm{~cm}^{3}$ of dimethylformamide (DMF) was introduced into a closed bottle to isolate the mixture from the air. The system was stirred for $12 \mathrm{~h}$ until polysulfone was completely solubilized. Next, a $0.625 \mathrm{~g}$ of polyvinylpyrrolidone (PVP) was added to this homogeneous solution, followed by the slow addition of an equivalent mass of $3 \times 10^{-3} \mathrm{~mol}$ of GA. The mixture was stirred for 3 to 4 days to solubilize the extractive agent to produce a homogeneous phase. The resulting phase was cast on a glass plate and then spread with a ruler. This glass plate was rapidly immersed in a bath containing distilled water. The solvent DMF leaves the membrane matrix and a rigid membrane in the form of a paper (phase inversion method) was obtained [38, 39]. After this operation, the GPM membrane was dried, its mass $(0.030 \mathrm{~g})$ and thickness $(\boldsymbol{l}=162 \mu \mathrm{m})$ were determined. Its total surface area $\left(10 \mathrm{~cm}^{2}\right)$ was measured and the concentration of the extractive agent $[\mathbf{T}]_{0}=0.20 \mathrm{~mol} \mathrm{~L}^{-1}$ was calculated.

PIM [40] was prepared by dissolving $10 \mathrm{~g}$ of polyvinyl alcohol (PVA) in a mixture of $20 \mathrm{~cm}^{3}$ of DMSO and $80 \mathrm{~cm}^{3}$ of distilled water. The mixture was stirred for $24 \mathrm{~h}$ at a temperature of $120^{\circ} \mathrm{C}$ to dissolve the PVA in the solution. In this homogeneous solution, an equivalent mass of $3 \times 10^{-3} \mathrm{~mol}$ of GA was added slowly under a condition of constant stirring to avoid polymer aggregation.
The resulting solution was poured carefully into a Petri dish and placed on a stove at a temperature range of 70 to $80{ }^{\circ} \mathrm{C}$ to evaporate the solvent completely. The heating temperature promotes solvent evaporation, allowing the polymer and extractive agent chains to come together. This step is important in the PIM membrane development process. The approach facilitates the cross-linking between the extractive agent and the polymer, inducing faster cross-linking kinetics [41]. The PIM obtained by this experimental protocol (heat vulcanization method) was homogenous, transparent, flexible, and mechanically strong [42, 43]. Its thickness was measured $(\boldsymbol{l}=228 \mu \mathrm{m})$ and the extractive agent concentration was calculated $\left([\mathbf{T}]_{0}=0.30 \mathrm{~mol} \mathrm{~L}^{-1}\right)$.

\section{Experimental protocol for the facilitated extraction of paracetamol}

The experimental cell (Additional file 1: Fig. S1) was used to carry out the facilitated extraction processes of the paracetamol compound. It consists of two compartments of identical volume separated by the produced membrane. The feed phase (F) contained the paracetamol solution in the concentration range of 0.01 to 0.08 $\left(\mathrm{mol} \mathrm{L}^{-1}\right)$, and the receiving phase $(\mathbf{R})$ contained distilled water $[40,44]$. The aqueous phase volume was $70 \mathrm{~cm}^{3}$ in each compartment. The system was immersed in a thermostatic bath (TB) containing water to keep the temperature constant throughout the experimental procedure. Homogeneity was ensured by using a multi-station magnetic stirrer.

Samples were collected from the receiving phase every $30 \mathrm{~min}$ and were measured at absorption maximum wavelength $\left(\chi_{\max }=244 \mathrm{~nm}\right)$. Knowing these values is necessary to calculate the membrane volume to determine the fixed concentration $[\mathbf{T}]_{0}$ of GA in the membrane phase.

\section{Results and discussion}

Before adopting these membranes for the facilitated extraction process of paracetamol substrate under different experimental conditions, various studies on their compositions and their morphologies were performed.

\section{Fourier transform-infrared (FTIR) analysis}

After drying the sample for $48 \mathrm{~h}$ to remove traces of residual water and solvent, the obtained membranes (PSU-PVP) and (PSU-PVP-AG) were characterized by the FTIR-spectroscopy technique (Fig. 1) to record the vibration bands corresponding to the membrane components. The PSU-PVP/GA membrane spectrum shows that all the characteristic absorption bands of the PSU + PVP support are present. These FT-IR spectra related to the PSU+PVP support membrane show the 


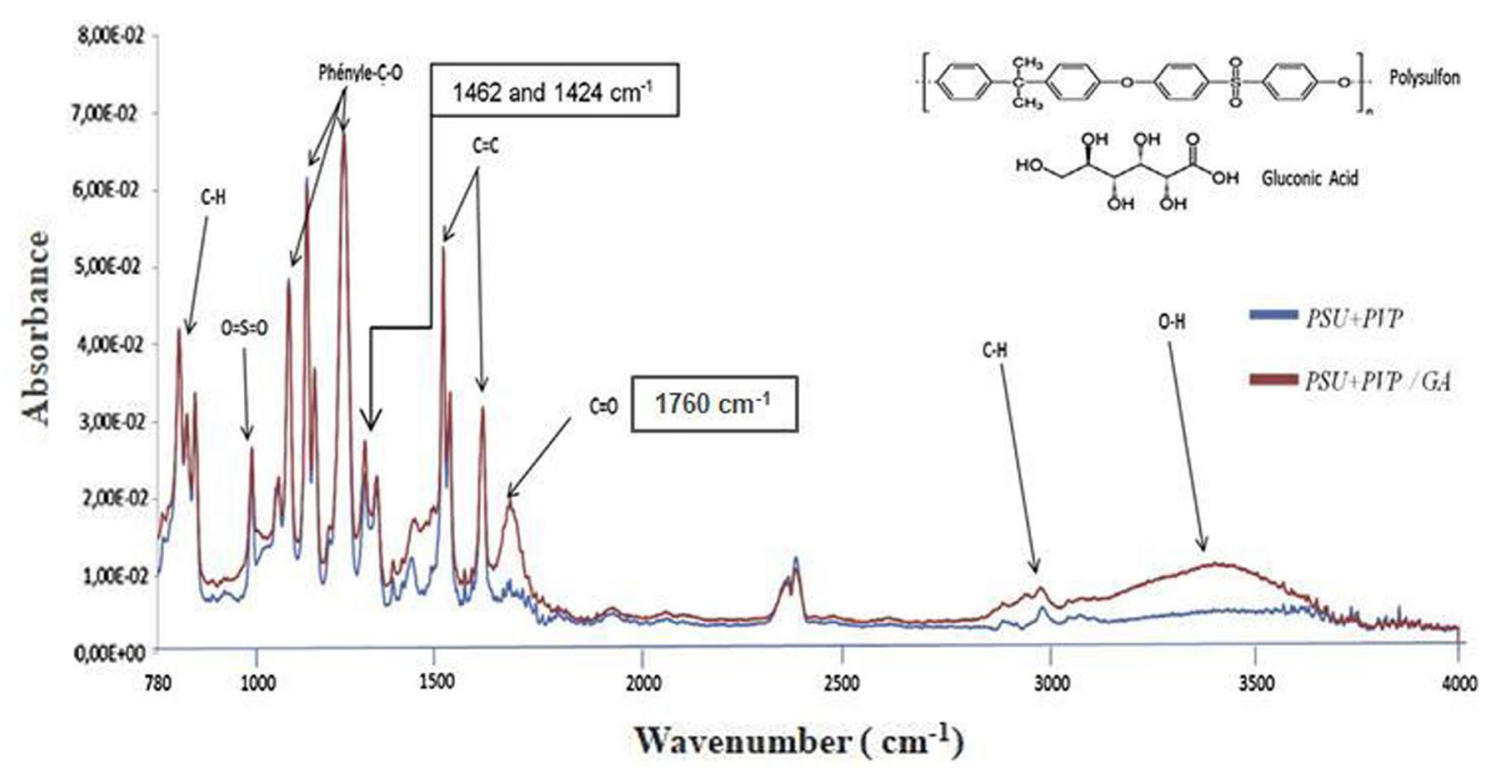

Fig. 1 The FT-IR spectrum for the PSU + PVP support and the PSU/PVP-GA membrane

peaks existing in the range of $700-1400 \mathrm{~cm}^{-1}$ correspond to PSU fingerprints, and two vibration peaks (1462 and $1424 \mathrm{~cm}^{-1}$ ), corresponding to the tertiary amine group of PVP copolymer. The spectrum also indicates the presence at around $3200-3600 \mathrm{~cm}^{-1}$ of a characteristic broad absorption band corresponding to the alcohol group $(\mathrm{OH})$. A peak at $1720 \mathrm{~cm}^{-1}$ was also observed, which was attributed to the vibration of the $\mathrm{C}=\mathrm{O}$ group of GA. These spectral evolutions proved that the extractive agent GA has been successfully integrated into the polymer matrix of the membrane.

The PIM was analyzed and characterized using the FT-IR and SEM in the same manner as the membrane described in the previous section. The results indicated and proved that the extractive agent; was trapped in the polymer matrix of the membrane, whose porosity increased with the concentration of the extractive agent.

Figure 2 shows the FTIR spectra of the PVA support and PVA-AG membranes. The common stretching vibration bands for some relative wavenumbers of the PVA polymer are: from 3283 to $3400 \mathrm{~cm}^{-1}$ attributed to the $\mathrm{OH}$ stretching vibration; from 2850 to $3000 \mathrm{~cm}^{-1}$ associated with the asymmetric stretching vibration of $\mathrm{CH}_{2}$ or $\mathrm{CH}$; the bands 1327 and $1424 \mathrm{~cm}^{-1}$ are due to the bending vibrations of $\mathrm{CH}_{2}$ and $\mathrm{CH}_{3}$. It is expected that the inclusion of AG agent in the PVA support increases the number of hydroxyl groups. As a result, the absorbance intensity band for $-\mathrm{OH}$ increases, and a new slightly intense peak for the vibration of the $\mathrm{C}=\mathrm{O}$ (carboxylic) bond appears at $1660 \mathrm{~cm}^{-1}$. A homogeneous dispersion of the extractive agent in the polymer matrix has a crosslinking effect due to covalent bonds' formation involving chemical interactions between polymer functional groups and organic acids at a high temperature $[45,46]$. On the other hand, several crosslinking methods have been published for different uses, since as a rule, all multifunctional compounds capable of reacting with hydroxyl groups can be used to obtain tridimensional networks in PVA $[47,48]$. In addition, Heat-treatment above the glass transition temperature is also used as means of achieving the same results $[49,50]$.

\section{Scanning electron microscopy (SEM) analysis}

Various samples of the elaborated membranes were visualized using the SEM technique. The samples were irradiated with an electron beam $(15 \mathrm{kV})$. This study was carried out under suitable magnification. Electrons were precisely focused for better visualization of the membrane surface and to properly record SEM micrographs of the upper surface of the polymer support (PSU + PVP) and the GPM membrane (PSU+PVP+GA). SEM images of the membranes with different compositions are grouped in the scheme of Fig. 3.

The SEM micrograph, presented in Fig. 3a, represents the morphology of the polymer support (PSU-PVP). A considerably smooth and dense surface without apparent porosity was observed. Figure $3 \mathrm{~b}$, c reveal that the extractive agent was efficiently grafted onto the membrane phase. It also influenced the structure, morphology, and porosity of the polymeric support. 


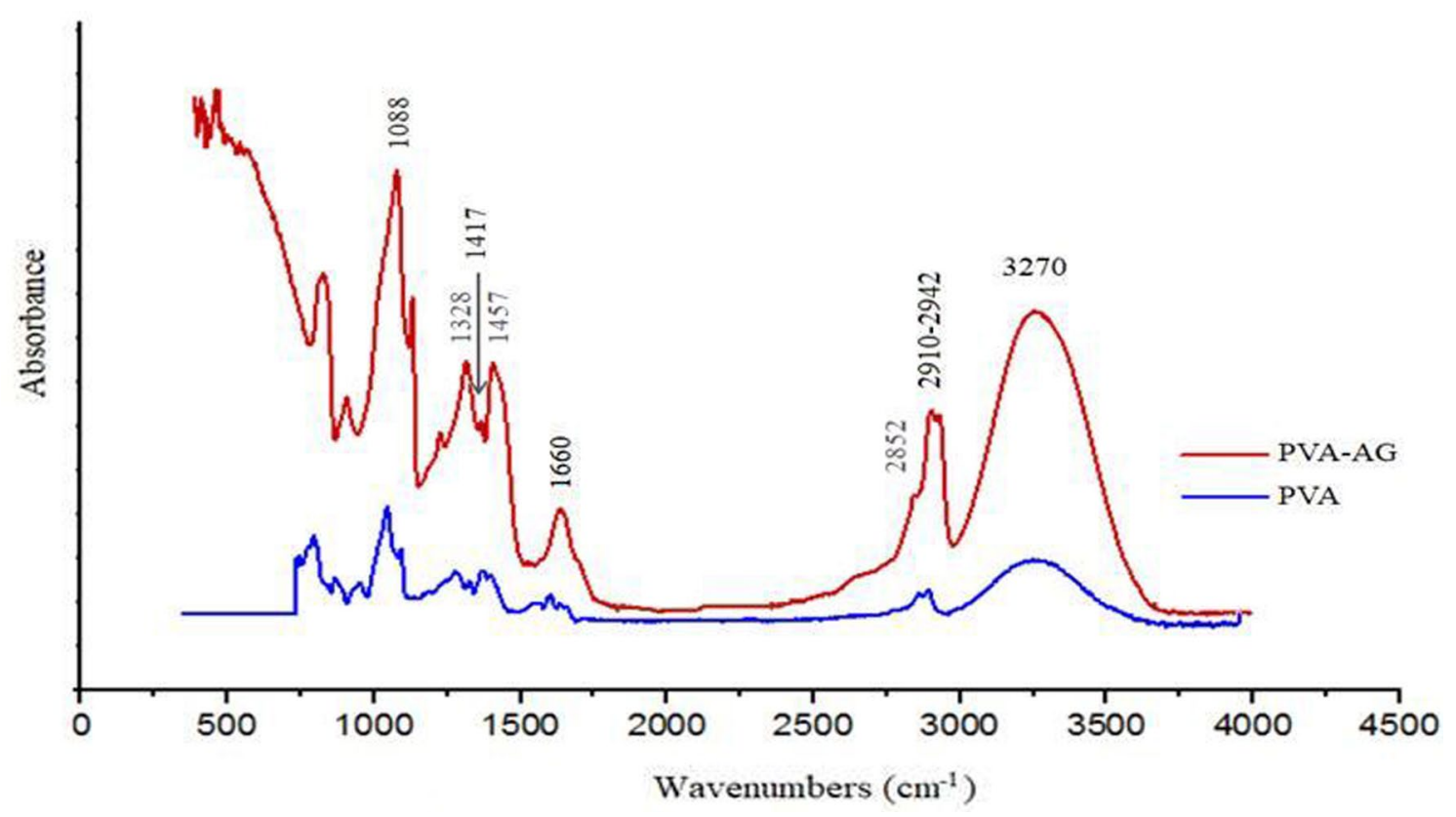

Fig. 2 The FT-IR spectrum for the PVA support and the PVA-GA membrane

The synthesized membrane contained pores along the membrane width (surface layers; Fig. 3b, c.

Figure 4 represents the SEM images relative to the two prepared PVA and PVA-AG. These SEM micrographs generally showed a remarkable change in morphology and porosity with the inclusion of the extractive agent in the polymeric support. Image (a) corresponds to the surface of the PVA support and clearly shows that the surface is homogeneous and smooth without apparent porosity. In contrast, the membrane modified by the inclusion of gluconic acid exhibits a clear porous membrane structure with a largely homogeneous porosity $(b, c)$ which are included in the polymer matrix.

\section{Degree of swelling}

The degree of swelling versus time was investigated by measuring the change in weight of the membrane before and after the swelling. The different sample membranes of $3 \times 3 \mathrm{~cm}$ were immersed into distilled water at $\mathrm{pH}=1,2$ and 3 for $48 \mathrm{~h}$. The membranes were taken out from the water every time tx, and carefully wiped with an absorbent paper, and quickly weighed. Increase in weight of the film was determined at preset time intervals until a constant weight was observed. The experiments were performed in triplicate, and average values were reported. The degree of swelling was calculated using the following equation $[51,52]$ :

$$
\mathrm{DS}(\%)=\frac{\mathrm{W}_{\mathrm{t}}-\mathrm{W}_{0}}{\mathrm{~W}_{0}} \times 100,
$$

where $\mathrm{W}_{\mathrm{t}}$ is the weight of film at time $t$, and $\mathrm{W}_{0}$ is the weight of film at time zero, and the value of $W_{t}$ is the result of the average of three weighings for each membrane.

Additional file 1: Figure S2 depicts the degree of swelling of the membranes PIM-based PVA and PIM-GA at $\mathrm{pH}=1,2$ and 3 . The results reveal that the $\mathrm{pH}$ of the medium doesn't play a role in affecting the swelling of membranes PIM-GA and improves mechanical properties [53, 54]. In addition, PIMs cross-linked by the GA have DS $\leq 23.5 \%$ compared to the membrane-based PVA only DS $<52 \%$. These confirm that the cross-linking effect with GA reduces the swelling degree. The efficiency of cross-linking and swelling ratio of the membranes are the main parameters to define its physicochemical properties.

The same experiment was conducted for GPM, and the membrane maintains practically the same weight after immersing in distilled water. The membrane has a wellaligned layer structure that does not swell. This result is probably due to the reason the polymer properties (hydrophobic), and the crosslinking type play an important role in effectively stabilizing the membrane and preventing them from swelling. Furthermore, this result was explained by Gupta et al. [55] that considered that 


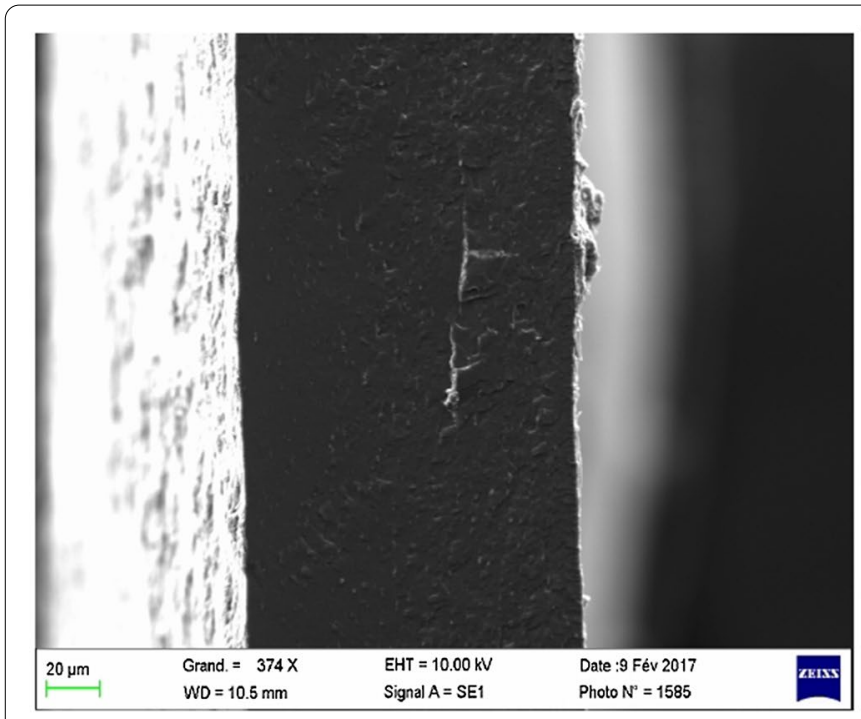

(a)

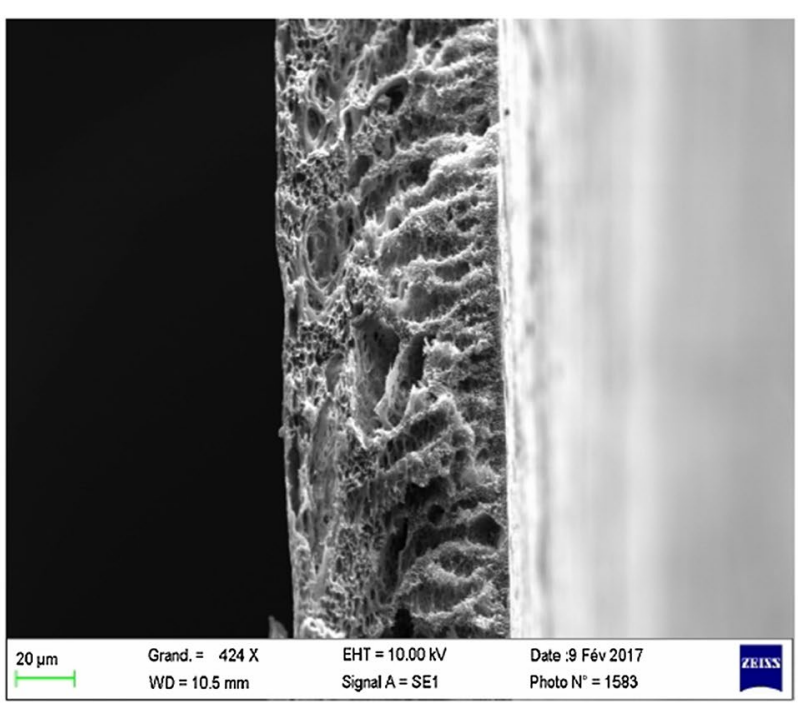

(b)

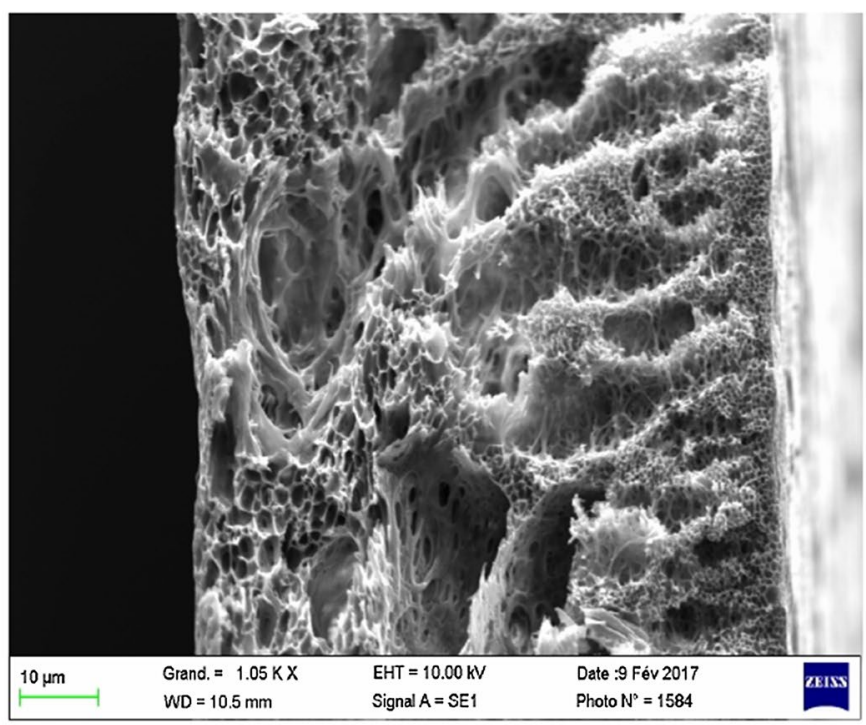

(c)

Fig. 3 SEM micrographs: a support polymer cross-section (PSU/PVP), b, c membrane cross-section (PSU/PVP-GA)

the crosslinking factor influences the swelling behavior and hence the resistivity of the membranes. The higher resistivity in both the 2 and $4 \%$ cross-linked membranes for higher graft levels is therefore due to the lower water content as observed in the swelling behavior.

\section{Theoretical models for quantification of processes}

The facilitated extraction processes for substrate $\mathbf{S}$ were conducted using an affinity polymer membrane. The process depends on the association and the dissociation of the substrate-extractive agent entity $(\mathbf{S T})$ at the membrane-solution interfaces and in the membrane phase during the substrate diffusion. To quantify the processes carried out and to study the performances of the adopted membranes, kinetic and thermodynamic models based on the first and second Fick's laws and a saturation law of the extractive agent $(\mathbf{T})$ by the substrate $(\mathbf{S})$ have been developed in the laboratory [37, 40, 56-58]. The equilibrium "association/dissociation" is presented according to the following relationships.

$$
\boldsymbol{P} \times\left(\mathbf{t}-\mathbf{t}_{\mathbf{I}}\right)=(\boldsymbol{l} \times \mathrm{V} / \mathrm{S})\left[1 / 2 \times \operatorname{Ln}\left(\mathbf{C}_{\mathbf{0}} / \mathbf{C}_{\mathbf{0}}-2 \mathbf{C}_{\mathbf{R}}\right)\right],
$$



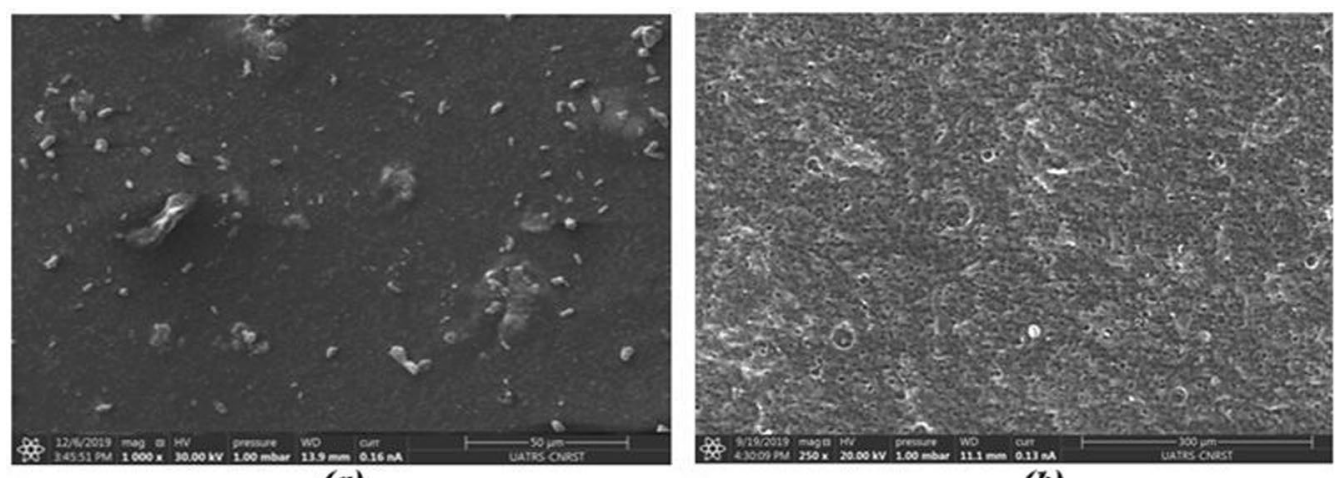

(a) (b)

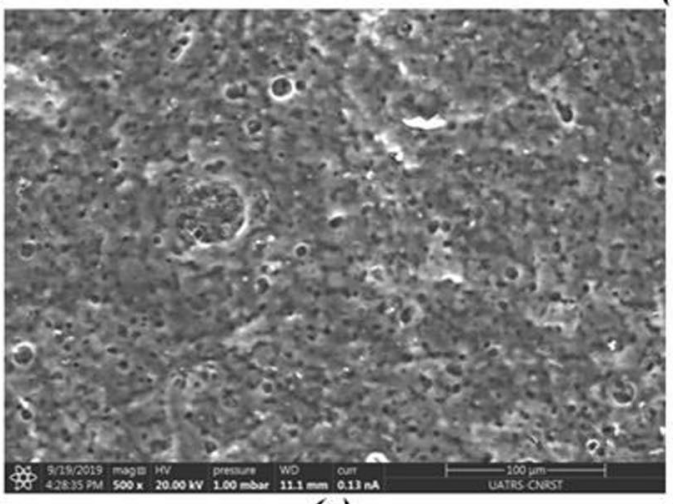

(c)

Fig. 4 SEM micrographs of support polymer surface (PVA) (a) and membrane surface (PVA-GA) (b)

$$
J_{0}=\left(D^{*} / l\right) \times\left[[T]_{0} \times K_{a s s} \times \mathbf{C}_{0} /\left(1+K_{a s s} \times \mathbf{C}_{0}\right)\right] .
$$

$\boldsymbol{l}$ : membrane thickness $(\mathrm{cm}), \mathbf{S}$ : membrane active area $\left(\mathrm{cm}^{2}\right)$ and $\mathbf{V}$ : receiving phase volume $\left(\mathrm{cm}^{3}\right)$.

$\mathbf{C}_{0}, \mathbf{C}_{\mathrm{R}}$, and $[\mathbf{T}]_{0}$ : initial substrate concentration in the feed phase $\left(\mathrm{mol} \mathrm{L}^{-1}\right)$, substrate concentration in the receiving phase at time $\boldsymbol{t}\left(\mathrm{mol} \mathrm{L}^{-1}\right)$ and extractive agent concentration in the organic phase $\left(\mathrm{mol} \mathrm{L}^{-1}\right)$, respectively.

$\boldsymbol{P}$ : membrane permeability $\left(\mathrm{cm}^{2} \mathrm{~s}^{-1}\right), \boldsymbol{J}_{0}$ : substance initial flux across the membrane $\left(\mathrm{mmol} \mathrm{s}^{-1} \mathrm{~cm}^{-2}\right), \boldsymbol{K}_{\text {ass }}$ : association constant of entity ST $\left(\mathrm{L} \mathrm{mol}^{-1}\right)$, and $\boldsymbol{D}^{*}$ : apparent diffusion coefficient of the substrate $S$ through the membrane phase $\left(\mathrm{cm}^{2} \mathrm{~s}^{-1}\right)$.

If the kinetic model is verified, after an induction time $\left(\mathbf{t}_{\mathbf{I}}\right)$, the function ( $-\operatorname{Ln}\left(\mathbf{C}_{\mathbf{0}}-2 \mathbf{C}_{\mathbf{R}}\right)$ versus time) evolves linearly. The slope $(\boldsymbol{a})$ of the obtained straight line allows the determination of the permeability parameter $\boldsymbol{P}$ according to the following equation $[59,60]$.

$$
\boldsymbol{P}=(\boldsymbol{a} * \boldsymbol{V} * \boldsymbol{l}) / \mathbf{2 S},
$$

The initial flux $J_{0}$ can be calculated from the permeability coefficient $\boldsymbol{P}$ by the following equation:

$$
J_{0}=\left(P \times C_{0}\right) / l .
$$

To determine the nature of the movement of the substrate $\mathrm{S}$ during its diffusion through the membrane phase and to elucidate the mechanism that governs the studied processes, it is necessary to determine the values of the microscopic parameters $\boldsymbol{D}^{*}$ and $\boldsymbol{K}_{\text {ass }}$. We used the Lineweaver-Burk method ( $\mathrm{L}-\mathrm{B})$ to linearize the expression in Eq. 2, according to the following equation [44, 61]:

$$
\mathbf{1} / J_{0}=\left(l / D^{*}\right) \times\left[\left(1 /\left([\mathbf{T}]_{0} \times K_{\text {ass }}\right)\right) \times\left(1 / \mathbf{C}_{0}\right)+\left(1 /[\mathbf{T}]_{0}\right)\right] .
$$

The linear evolution of the term $1 / J_{0}=f\left(1 / C_{0}\right)$ (from Eq. 5) allows us to confirm that the thermodynamic model is based on the interaction of the substrate (S) with the extractive agent $(\mathbf{T})$. The interaction in the membrane phase was checked. Similarly, the values of slopes (p) and intercepts (OO) of the obtained straight line segments are used to calculate the values of $D^{*}$ and $\boldsymbol{K}_{\text {ass }}$ according to the following equation:

$$
K_{\text {ass }}=\text { intercept }(O O) / \text { slope } \text { and } D^{*}=(l / O O) \times\left(1 /[\mathrm{T}]_{0}\right) \text {. }
$$


The initial flux is related to the temperature factor by the Arrhenius law [62, 63], according to the following equation:

$$
J_{0}(T)=A_{j} \exp \left(-E_{a} / R T\right),
$$

$\boldsymbol{R}$ : gas constant $\left(8.314 \mathrm{~J} \mathrm{~mol}^{-1} \mathrm{~K}^{-1}\right) . A_{j}$ : proportional term to the favorable interactions $\left(\mathrm{mol}^{-1} \mathrm{~s}^{-1} \mathrm{~m}^{2}\right), E_{\boldsymbol{a}}$ : transition state activation energy of the formation-dissociation reaction of the entity $(\boldsymbol{T S})\left(\mathrm{J} \mathrm{mol}^{-1}\right)$.

The expression was linearized according to the following equation:

$$
\ln J_{0}=\left(\left(\left(-E_{a}\right) / R\right) \times(1 / T)+\ln A_{j}\right) .
$$

The values of activation parameters $\boldsymbol{E}_{\boldsymbol{a}}$ and $\boldsymbol{A} \boldsymbol{j}$ were determined from the slope and the intercept of the linear function $\operatorname{Ln}\left(J_{0}\right)=\mathrm{f}(1 / \mathrm{T})$. According to the transition state theory (Eyring theory), these values allow the calculation of the activation enthalpy $\Delta H^{\#}\left(\mathrm{~J} \mathrm{~mol}^{-1}\right)$ and entropy $\Delta S^{\#}\left(\mathrm{~J} \mathrm{~K}^{-1} \mathrm{~mol}^{-1}\right)$ parameters from the following equation:
Influence of the initial substrate concentration $\left(C_{0}\right)$ on the performance of the developed membranes Before adopting PIM-GA and GPM-AG, we have carried out experiments related to the extraction of paracetamol through PVA and PSU-PVP membranes without the extractive agent. We have noticed that these membranes are impermeable and confirm that the extractive agent is essential, which is responsible for interactions with the target species and their diffusion through the membrane phase.

In this section, we have examined the effect of $\mathbf{C}_{\mathbf{0}}$ on the evolution of macroscopic parameters $\boldsymbol{P}$ and $\boldsymbol{J}_{\mathbf{0}}$ relative to the facilitated extraction processes of paracetamol through all the developed membranes. Indeed, we have studied the processes at different $\mathrm{C}_{\mathbf{0}}: \mathbf{0 . 0 8}, \mathbf{0 . 0 4}, 0.02$, and $0.01\left(\mathrm{~mol} \mathrm{~L}^{-1}\right)$ at $\mathrm{pH}=1$ and $\mathrm{T}=298 \mathrm{~K}$. At all concentrations, the kinetic model has been verified, and the function $-\operatorname{Ln}\left(\mathbf{C}_{0}-2 \mathbf{C}_{\mathbf{R}}\right)=f(\mathbf{t})$ generated straight lines (Fig. 5). The values of $\boldsymbol{P}$ and $\boldsymbol{J}_{\mathbf{0}}$ were determined from the slopes of the straight lines (according to the expressions in Eqs. 3 and 4), presented in Table 1.

$$
\boldsymbol{\Delta} \boldsymbol{H}^{\neq}=\boldsymbol{E}_{\boldsymbol{a}}-2500\left(\mathrm{~J} \mathrm{~mol}^{-1}\right) \text { and } \boldsymbol{\Delta} \boldsymbol{S}^{\neq}=\boldsymbol{R}\left(\boldsymbol{l n} \boldsymbol{A}_{j}-30.46\right)\left(\mathrm{J} \mathrm{K}^{-1} \mathrm{~mol}^{-1}\right) \text { at } 298^{\circ} \mathrm{K} \text {. }
$$

The thermodynamic enthalpy parameter $\Delta \boldsymbol{H}^{\neq}{ }_{t h}$ $\left(\mathrm{Kj} \mathrm{mol}^{-1}\right)$ represents the amount of energy exchanged during the equilibrium reaction related to the formation of the ST entity. The value of this parameter is determined directly from the slope of the linear representation of Van't Hoff's law (Eq. 10).

$$
\ln \left(K_{\text {ass }}\right)=\left(-\left(\Delta H_{t h}^{\neq}\right) / \mathbf{R T}\right)+\text { cste. }
$$

On the other hand, according to the transition state theory, for an elementary reaction, this important thermodynamic parameter is related to the activation enthalpies, association $\Delta \boldsymbol{H}^{\neq}$ass , and dissociation $\Delta \boldsymbol{H}^{z_{\text {diss }}}$ $\left(\mathrm{Kj} \mathrm{mol}^{-1}\right)$ by the following relation:

$$
\Delta \boldsymbol{H}_{\text {th }}^{\neq}=\Delta \boldsymbol{H}_{\text {ass }}^{\neq}-\Delta \boldsymbol{H}_{\text {diss }}^{\neq}
$$

Analysis of the results grouped in Table 1 demonstrates that the used membranes are effective for paracetamol extraction. Based on the obtained values of macroscopic parameters $\left(\boldsymbol{P}\right.$ and $\left.\boldsymbol{J}_{0}\right)$, the PIM membrane was more efficient than the GPM counterpart. However, it was noticed that the permeability $\boldsymbol{P}$ of the adopted membranes varies inversely with the initial paracetamol concentration in the feed phase $\mathrm{C}_{0}$, and an increase in the substrate concentration leads to a decrease in the parameter $\boldsymbol{P}$. However, the initial flux of paracetamol $\left(J_{0}\right)$ through each of the membranes increases with the substrate concentration $\mathrm{C}_{0}$. This reason can explain this is that during facilitated extraction of the substrate across the membrane,

\begin{tabular}{|c|c|c|c|c|}
\hline \multirow{2}{*}{$\begin{array}{l}\text { Membrane type } \\
\mathrm{C}_{0} \text { initial concentration }\left(\mathrm{mol} \mathrm{L}^{-1}\right)\end{array}$} & \multicolumn{2}{|l|}{ PIM } & \multicolumn{2}{|l|}{ GPM } \\
\hline & $P * 10^{7}\left(\mathrm{~cm}^{2} \mathrm{~s}^{-1}\right)$ & $J_{0} * 10^{5}\left(\mathrm{mmol} \mathrm{s}^{-1} \mathrm{~cm}^{-2}\right)$ & $P * 10^{7}\left(\mathrm{~cm}^{2} \mathrm{~s}^{-1}\right)$ & $\begin{array}{l}J_{0}^{*} 10^{5} \\
\left(\mathrm{mmol} \mathrm{s}{ }^{-1} \mathrm{~cm}^{-2}\right)\end{array}$ \\
\hline 0.08 & 18.112 & 0.636 & 9.374 & 0.462 \\
\hline 0.04 & 20.235 & 0.355 & 10.053 & 0.248 \\
\hline 0.02 & 20.962 & 0.184 & 10.458 & 0.129 \\
\hline 0.01 & 21.446 & 0.094 & 10.851 & 0.067 \\
\hline
\end{tabular}
the association/dissociation mechanism of paracetamol with the extractive agent is faster when the initial substrate concentration is higher. This is due to the high

Table 1 Evolution of $P$ and $J_{0}$ parameters for extraction oriented processes of the paracetamol substrate at T=298 $\mathrm{K}$ 


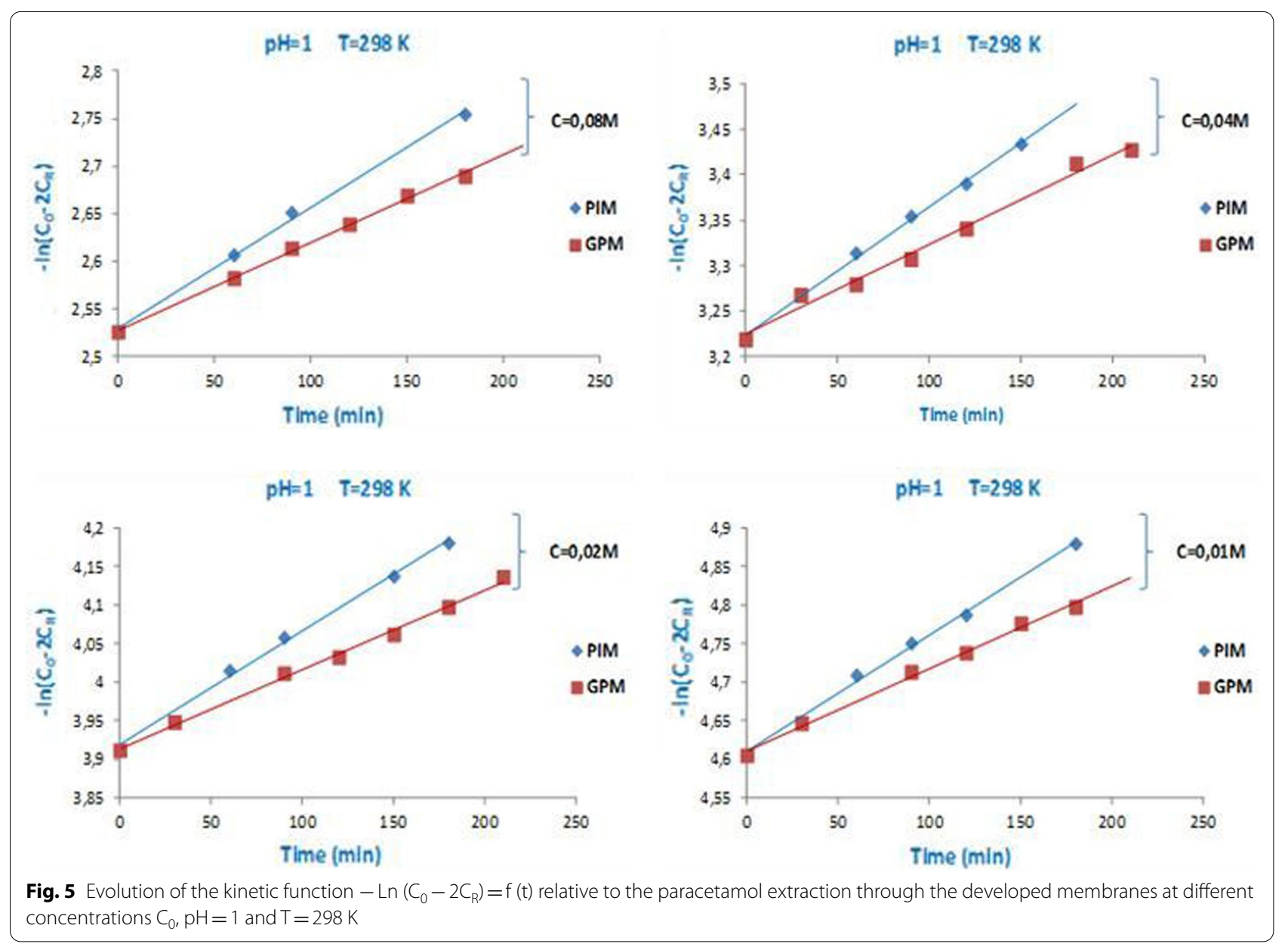

Table 2 Evolution of $P$ and $J_{0}$ with $\mathrm{pH}$ during the extraction of paracetamol at $\mathrm{T}=298 \mathrm{~K}$

\begin{tabular}{|c|c|c|c|c|c|}
\hline \multirow[t]{2}{*}{$\mathrm{pH}$} & \multirow[t]{2}{*}{$C_{0}\left(\mathrm{~mol} \mathrm{~L}^{-1}\right)$} & \multirow{2}{*}{$\begin{array}{l}\text { PIM } \\
P * 10^{7}\left(\mathrm{~cm}^{2} \mathrm{~s}^{-1}\right)\end{array}$} & \multicolumn{3}{|l|}{ GPM } \\
\hline & & & $\begin{array}{l}J_{0}^{*} 10^{5} \\
\left(\mathrm{mmol} \mathrm{s}^{-1} \mathrm{~cm}^{-2}\right)\end{array}$ & $P^{*} 10^{7}\left(\mathrm{~cm}^{2} \mathrm{~s}^{-1}\right)$ & $\begin{array}{l}J_{0}^{*} 10^{5} \\
\left(\mathrm{mmol} \mathrm{s}^{-1} \mathrm{~cm}^{-2}\right)\end{array}$ \\
\hline \multirow[t]{4}{*}{1} & 0.08 & 18.112 & 0.635 & 9.373 & 0.462 \\
\hline & 0.04 & 20.235 & 0.355 & 10.053 & 0.248 \\
\hline & 0.02 & 20.962 & 0.184 & 10.458 & 0.129 \\
\hline & 0.01 & 21.446 & 0.094 & 10.851 & 0.067 \\
\hline \multirow[t]{4}{*}{2} & 0.08 & 16.444 & 0.577 & 8.929 & 0.440 \\
\hline & 0.04 & 20.178 & 0.354 & 9.866 & 0.243 \\
\hline & 0.02 & 20.734 & 0.182 & 10.224 & 0.126 \\
\hline & 0.01 & 20.962 & 0.092 & 10.625 & 0.065 \\
\hline \multirow[t]{4}{*}{3} & 0.08 & 16.159 & 0.567 & 8.713 & 0.429 \\
\hline & 0.04 & 19.693 & 0.345 & 9.771 & 0.241 \\
\hline & 0.02 & 20.491 & 0.180 & 10.080 & 0.124 \\
\hline & 0.01 & 20.620 & 0.090 & 10.536 & 0.065 \\
\hline
\end{tabular}



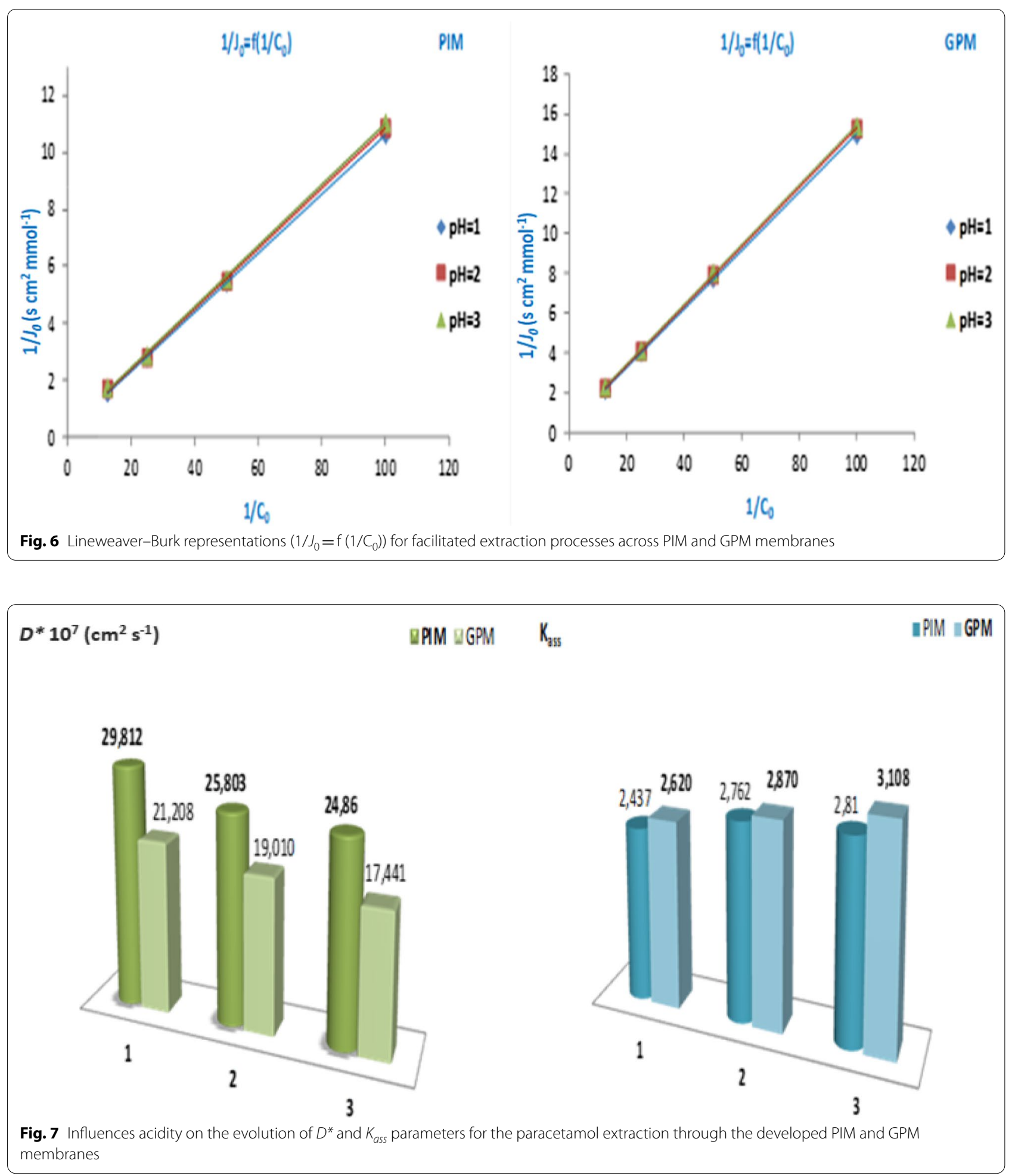

difference in concentration between the feed and receiving phase (concentration gradient). Moreover, the results obtained for $\boldsymbol{P}$ indicate that this parameter is influenced by the competition of the substrate molecules to diffuse through the membrane phase. This evolution of the values of the parameters $\boldsymbol{P}$ and $\boldsymbol{J}_{\boldsymbol{0}}$ related to this oriented process has been observed and indicated by some previous works for similar processes related to the extraction of some organic compounds and metal ions [64-67]. 
Table 3 Evolution of $P$ and $J_{0}$ parameters according to the medium temperature for extraction oriented processes of paracetamol

\begin{tabular}{|c|c|c|c|c|c|}
\hline \multirow[t]{2}{*}{$\mathrm{T}(\mathrm{K})$} & \multirow[t]{2}{*}{$C_{0}\left(\mathrm{~mol} \mathrm{~L}^{-1}\right)$} & \multicolumn{2}{|l|}{ PIM } & \multicolumn{2}{|l|}{ GPM } \\
\hline & & $P * 10^{7}\left(\mathrm{~cm}^{2} \mathrm{~s}^{-1}\right)$ & $\begin{array}{l}J_{0} * 10^{5}\left(\mathrm{mmol} \mathrm{s}^{-}\right. \\
\left.\mathrm{cm}^{-2}\right)\end{array}$ & $P * 10^{7}\left(\mathrm{~cm}^{2} \mathrm{~s}^{-1}\right)$ & $\begin{array}{l}J_{0}^{*} 10^{5} \\
\left(\mathrm{mmol} \mathrm{s}{ }^{-1} \mathrm{~cm}^{-2}\right)\end{array}$ \\
\hline \multirow[t]{4}{*}{298} & 0.08 & 18.112 & 0.635 & 9.373 & 0.462 \\
\hline & 0.04 & 20.235 & 0.355 & 10.053 & 0.248 \\
\hline & 0.02 & 20.962 & 0.184 & 10.458 & 0.129 \\
\hline & 0.01 & 21.446 & 0.094 & 10.851 & 0.067 \\
\hline \multirow[t]{4}{*}{303} & 0.08 & 19.751 & 0.693 & 10.465 & 0.516 \\
\hline & 0.04 & 22.273 & 0.391 & 12.043 & 0.297 \\
\hline & 0.02 & 22.886 & 0.201 & 12.189 & 0.150 \\
\hline & 0.01 & 23.299 & 0.102 & 12.546 & 0.077 \\
\hline \multirow[t]{4}{*}{308} & 0.08 & 20.321 & 0.713 & 11.262 & 0.555 \\
\hline & 0.04 & 24.410 & 0.428 & 12.200 & 0.301 \\
\hline & 0.02 & 24.553 & 0.215 & 12.673 & 0.156 \\
\hline & 0.01 & 24.738 & 0.108 & 12.934 & 0.080 \\
\hline
\end{tabular}

\section{Acidity factor influence on the evolution of paracetamol extraction processes}

To investigate the effect of acidity (feed and receiving aqueous solutions) on extraction efficiency through the adopted membranes, a series of experiments were performed at different $\mathrm{pH}(\mathbf{1}, \mathbf{2}$, and $\mathbf{3})$. Different substrate concentrations $\left(0.01-0.08 \mathrm{~mol} \mathrm{~L}^{-1}\right)$ were used for the experiments. The values of the macroscopic parameters $\boldsymbol{P}$ and $\boldsymbol{J}_{\mathbf{0}}$ were determined at each $\mathrm{pH}$ value (Table 2 ). The
Lineweaver-Burk (L-B) representation $1 / J_{0}=f\left(1 / \mathbf{C}_{0}\right)$ was plotted using the values of initial fluxes. The slopes and intercepts of the straight lines are shown in Fig. 6. The $\boldsymbol{D}^{*}$ and $\boldsymbol{K}_{\text {ass }}$ values (microscopic parameters) were estimated. The results are presented as histograms in Fig. 7.

According to the results grouped in Table 2, it is clear that the $\mathrm{pH}$ of the aqueous solutions does not significantly influence the extraction oriented processes of

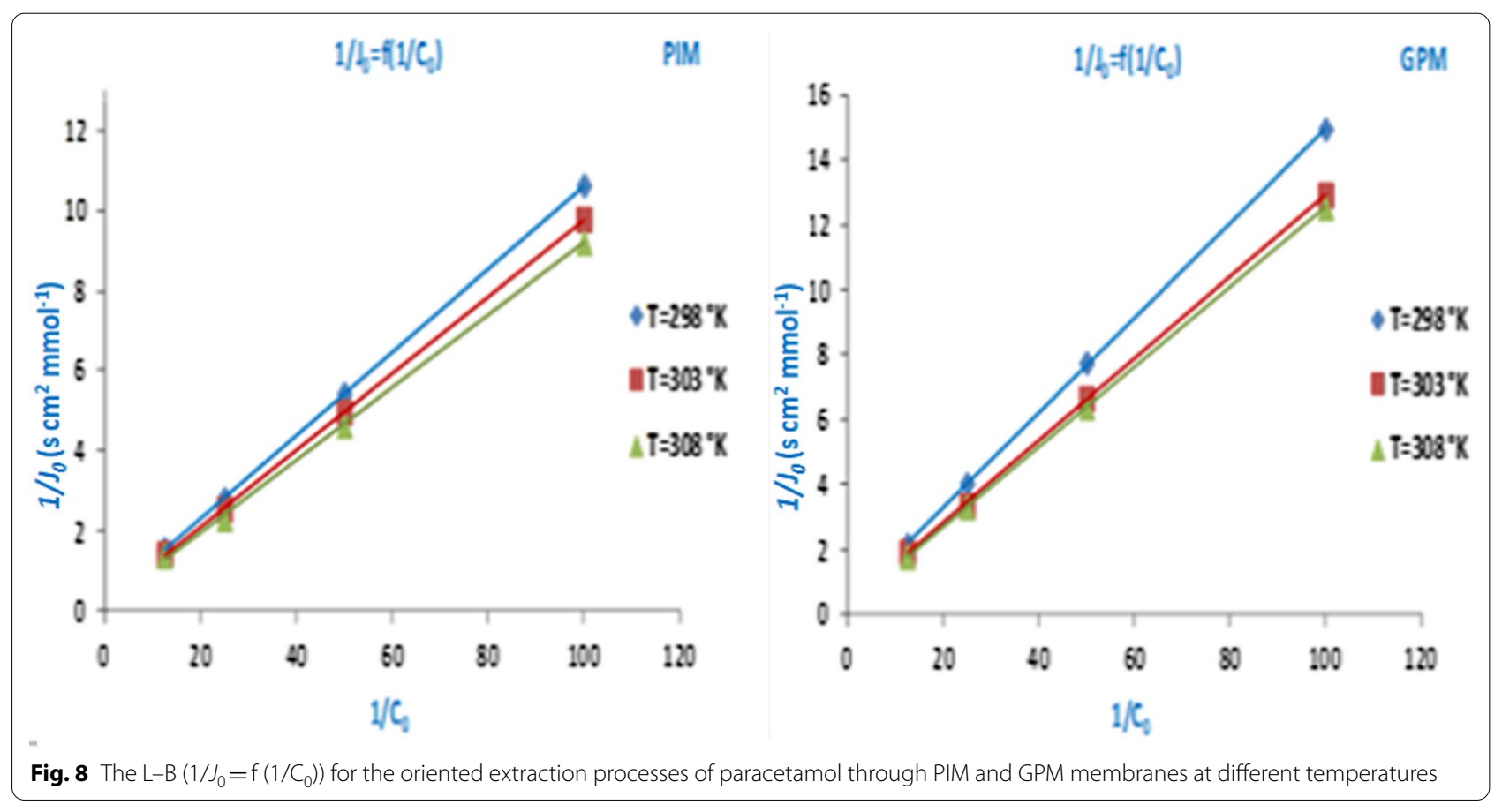




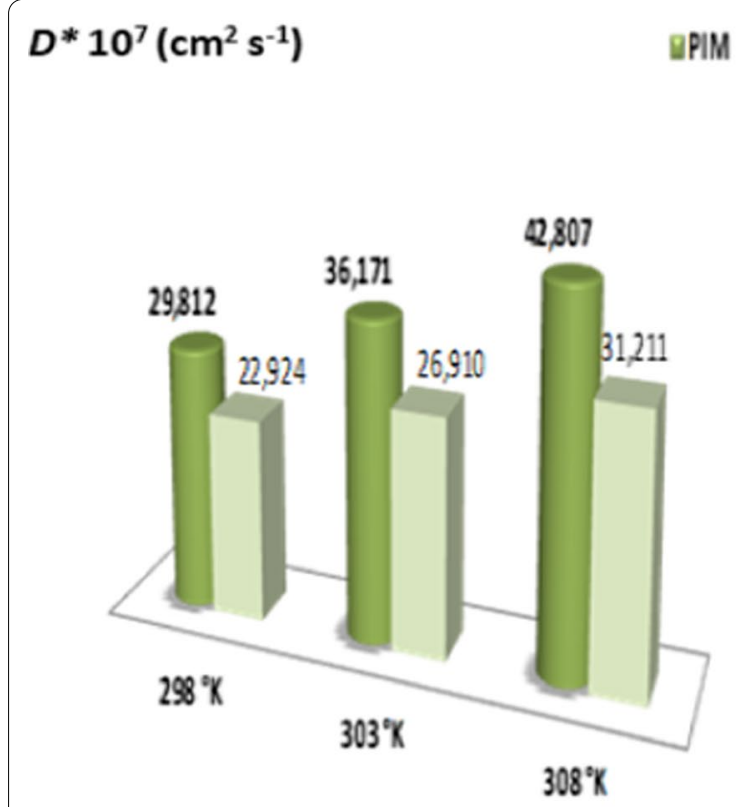

\section{$\kappa_{e s}$}

Fig. 9 Evolution of specific $D^{*}$ and $K_{\text {ass }}$ parameters according to the medium temperature for the facilitated extraction process of paracetamol through elaborated membranes

paracetamol. On the other hand, it has been confirmed that the performance of the PIM membrane is better than that of the GPM counterpart at 3 acidic mediums.

As shown from Fig. 7, the apparent diffusion coefficient $D^{*}$ and association constant $K_{\text {ass }}$ vary inversely. The highest values of $\boldsymbol{D}^{*}$ and the lowest $\boldsymbol{K}_{\text {ass }}$ values are obtained for the most efficient membrane (PIM). These results explain the performances of the developed polymer membranes. The low values of $\boldsymbol{K}_{\text {ass }}$ explain that the entity (Paracetamol-GA) in the membrane phase of PIM is less stable, which reflects by a higher diffusion in contrast to GPM. The high values of $\boldsymbol{D}^{*}$ propose, firstly, that the diffusion of the substrate through the PIM was conditioned by successive interactions of substrate molecules with semi-mobile interaction sites of extractive agent in the membrane phase. Secondly, the passage of paracetamol through the GPM is a diffusion movement by successive jumps of substrate molecules from one site to another of fixed-sites of the extractive agent (Additional file 1: Fig. S3).

\section{Temperature influence on the evolution of oriented extraction processes of paracetamol}

To confirm the previous results and determine the activation and thermodynamic parameters we examined the temperature factor influence on the evolution of the extraction process. The experiments were conducted at better acidity $(\mathbf{p H}=\mathbf{1}), \mathbf{C}_{\mathbf{0}}$ was varied in the range of
0.01 to $0.08 \mathrm{~mol} \mathrm{~L}^{-1}$ and at different temperatures (298, 303 , and $308 \mathrm{~K})$.

The values of macroscopic parameters $\boldsymbol{P}$ and $\boldsymbol{J}_{0}$ have been summarized in Table 3 . The data reveals the impact of temperature on the facilitated extraction processes employed for paracetamol extraction. In addition, an increase in temperature leads to an increase in membrane performance. It was noted that the permeability and initial fluxes through the PIM membrane were higher than the permeability of the GPM membrane at all temperatures. To complete our study, we plotted the L-B curve $\left(1 / J_{0}=\mathrm{f}\left(1 / \mathbf{C}_{0}\right)\right)$ (Fig. 8$)$.

The linear evolution verified the adopted thermodynamic model and slopes and intercepts of the straight lines were used to determine the values of the apparent diffusion coefficient $D^{*}$ and the association constant $\boldsymbol{K}_{\text {ass }}$. These two parameters are relative to the movement of the paracetamol molecules when they diffuse through each membrane. The values for these specific parameters and their evolution as a function of temperature are presented by the histograms in Fig. 9 .

The results obtained for the microscopic parameters (Fig. 9) indicate the inverse evolution of $\boldsymbol{K}_{\text {ass }}$ and $\boldsymbol{D}^{*}$. Therefore, confirming that an increase in the temperature leads to a decrease in stability of the ST entity formed in the membrane phase by interaction between substrate $\mathrm{S}$ and extractive agent $\mathrm{T}$. Indeed, the low stability of the entity (ST) (translated by low values of $\boldsymbol{K}_{\text {ass }}$ ) explain the 


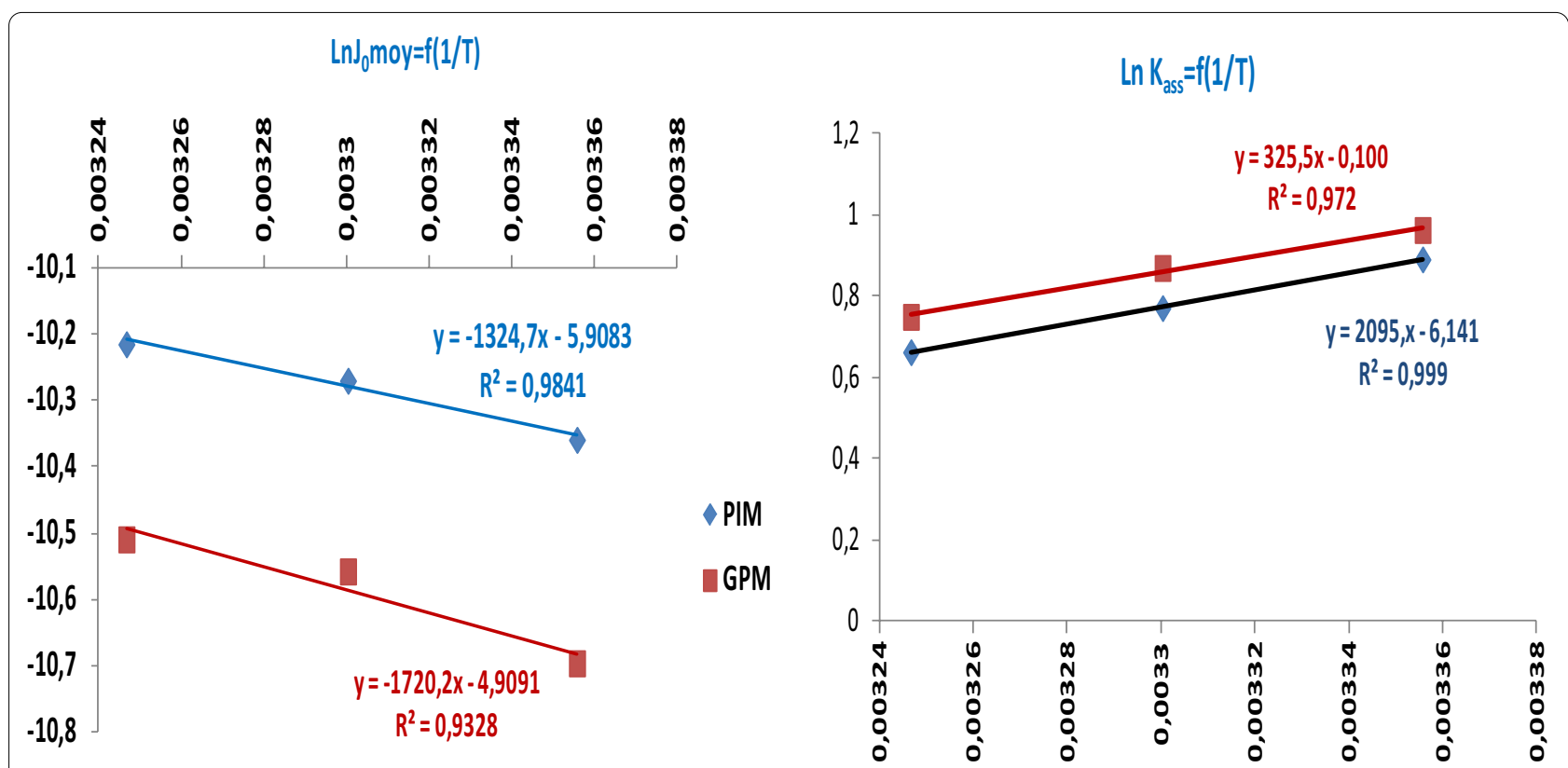

Fig. 10 Evolution of Arrhenius and Van't Hoff relationships for the paracetamol extraction processes through the PIM and GPM membranes

Table 4 Activation and thermodynamic parameters corresponding to the transition state of the extraction process occurring through developed membranes

\begin{tabular}{|c|c|c|c|c|c|}
\hline $\begin{array}{l}\text { Activation } \\
\text { parameters }\end{array}$ & $E_{a}\left(\mathrm{~kJ} \mathrm{~mol}^{-1}\right)$ & $\Delta H_{\text {ass }}^{\#}\left(\mathrm{~kJ} \mathrm{~mol}^{-1}\right)$ & $\Delta S^{\#}\left(\mathrm{~J} \mathrm{~mol}^{-1} \mathrm{~K}^{-1}\right)$ & $\Delta H_{t h}\left(\mathrm{~kJ} \mathrm{~mol}{ }^{-1}\right)$ & $\Delta H_{\text {diss }}^{\#}\left(\mathrm{~kJ} \mathrm{~mol}^{-1}\right)$ \\
\hline PIM & 11.008 & 8.531 & -302.221 & -17.420 & 25.952 \\
\hline GPM & 14.295 & 11.818 & -293.918 & -16.286 & 28.10 \\
\hline
\end{tabular}

faster substrate diffusion $(\mathbf{S})$. The high $\boldsymbol{D}^{*}$ and lower $\boldsymbol{K}_{a s s}$ values obtained at high temperatures can be potentially explained by improved membranes performance. The high values of apparent diffusion coefficient $\left(D^{*}\right)$, might indicate that the movement of paracetamol molecule across the organic phase of PIM and GPM membranes containing GA as an extractive agent is not pure diffusion.

In addition, according to the reviews and papers published by Hlaibi et al. [68, 69] related to the extraction of some organic compounds through SLM membranes types indicate identical evolutions for the specific parameters $\boldsymbol{K}_{\text {ass }}$ and $\boldsymbol{D}$ * with a similar mechanism. Moreover, the values of $\boldsymbol{K}_{\text {ass }}$ and $\boldsymbol{D}^{*}$ parameters show that in the membrane phase, the interactions between molecules of organic compounds and extractive agent are low. In contrast, the values of apparent diffusion coefficient $\left(D^{*}\right)$ are high. At this step of the studies, we confirmed that the PIM membrane is more efficient than its counterpart GPM in terms of performance.

\section{Activation and thermodynamic parameters for the extraction studied processes}

To elucidate the energetic or kinetic aspect that controls the mechanism of the studied processes, and to explain the performances of the prepared membranes, it is necessary to determine the values of the activation and thermodynamic parameters $\left(\boldsymbol{E}_{\boldsymbol{a}}, \Delta \boldsymbol{H}_{\text {ass }}^{\neq}, \Delta \boldsymbol{S}^{\neq}, \Delta \boldsymbol{H}^{\boldsymbol{F}^{\prime}}\right.$ diss and $\left.\Delta \boldsymbol{H}^{\neq}{ }_{\boldsymbol{t h}}\right)$ corresponding to the transition state of the substrate diffusion step across each organic membrane phase. For this, we have studied the evolution of $\boldsymbol{J}_{\mathbf{0}}$ and $\boldsymbol{K}_{\text {ass }}$ values with temperature factor according to Arrhenius $\left(\operatorname{Ln}\left(\boldsymbol{J}_{\mathbf{0 m o y}}\right)=\mathrm{f}(1 / \mathrm{T})\right)$ and Van't Hoff $\left(\operatorname{Ln}\left(\boldsymbol{K}_{\text {ass }}\right)=\mathrm{f}\right.$ $(1 / \mathrm{T})$ relationships (Eqs. 8 and 10) respectively (Fig. 10). The slopes and intercepts determined from the obtained straight line segments were used to determine the values of the activation and the thermodynamic parameters.

Table 4 presents the values of all the activation and thermodynamic parameters. Analysis of the activation parameters indicates that the transition state corresponding to the diffusion step requires little energy $\left(\boldsymbol{E}_{\boldsymbol{a}}\right.$ and $\Delta \boldsymbol{H}_{\text {ass }}^{\neq}$). On the other hand, the negative activation entropy $\left(\Delta S^{\mp}\right)$ indicates that the transition state is 
perfectly ordered, depends on the substrate and extractive agent structures, and the orientation of their interaction sites. These results indicate that a favorable orientation of the interaction sites is required to achieve a good association between the paracetamol molecules and GA in the transition state with the bidentate sites $\left(\Delta S^{\#}=-300 \mathrm{~J} \mathrm{~mol}^{-1} \mathrm{~K}^{-1}\right.$ ) (Additional file 1: Figs. S4 and S5). On the other hand, the low values of the important parameters $\left(\Delta \boldsymbol{H}^{\ddagger}{ }_{\text {ass }}\right.$ and $\left.\boldsymbol{\Delta} \boldsymbol{H}^{\boldsymbol{F}_{\text {diss }}}\right)$ reveal the kinetic control aspect of the mechanisms of the oriented processes leading to good membrane performances even at low temperatures. This kinetic control aspect for the diffusion of paracetamol molecules through affinity polymer membranes can be described the structure of the molecules and the pharmacological and biological activities of these molecules that diffuse through cell membranes at a constant temperature.

The very low values of $\left(\boldsymbol{E a}, \Delta \boldsymbol{H}_{\text {ass }}\right.$, and $\Delta \boldsymbol{H}^{\ddagger}$ diss $)$ parameters relative to the facilitated extraction process across PIM-GA explain the good performance of this membrane type against to GPM-GA counterpart. Moreover, they confirm the influence of temperature factor and the inverse evolution of $\boldsymbol{K}_{\text {ass }}$ and $\boldsymbol{D}^{*}$ parameters. They also indicate that the substrate migration through the membrane phase was done by a mechanism of successive jumps of substrate molecules with semi-mobile interaction sites of the extractive agent in the PIM membrane phase. In contrast, the diffusion of paracetamol across the GPM is a movement of successive jumps from one site to another of the extractive agent fixedsites. Indeed, several studies $[28,70,71]$ confirmed these types of mechanisms in which the substrate moves while binding successively to several semi-mobile and fixed extractive agents (considered as a complexation site). Reversible association-dissociation reactions leading to the formation and decomposition of an unstable "hostguest" complex were carried out.

\section{Test for membrane stability}

The stability test of elaborated PIM and GPM has been conducted under several conditions. The highest stability was observed at the tested $\mathrm{pH}$ and temperature during the extraction of paracetamol. The PVA and GPM membranes stability in an acidic medium was determined by repeating every 1-3 days at the end of the workday, an extraction of paracetamol was conducted in the same conditions. During every day, the membrane was also used for other experiments. The membrane was stable for about 6 months. This result is in good accordance with experiments described in the previous study $[61,70]$. Moreover, after 6 months, the membranes were used for the same experiments without losing their effectiveness. They provided practically the same results as the obtained for the first experiment (A gap of $4.2 \%$ in the case of PIM and 3.8\% for GPM). However, no degradation of membrane morphology occurred during the investigation. Therefore, it can be affirmed that the PIM and GPM membranes based on PVA and PSU with Gluconic acid as extractive agent manifested a stable characteristic with a good reproducibility during the proposed period. Additional file 1: Fig. S6 presented the evolution of the permeability relative to the facilitated extraction processes of paracetamol at $\mathrm{C}_{0}=0.08 \mathrm{M}, \mathrm{pH}=1$ and $\mathrm{T}=298 \mathrm{~K}$, during a period of 6 months. Moreover, the membranes stability was also evaluated in terms of membrane mass change [72, 73]. Before and after the experiments, PIM and GPM membrane pieces were carefully weighed, and it was found a mass loss between 7 and 18\% of the total weight for PIM and 5-11\% for GPM. Hence, these results provide the use of these membranes since they preserve their performance features, such as low cost, and the possibility to prepare selective membranes, while providing the necessary stability to perform longterm experiments.

The membranes obtained after the extraction process were recovered and conditioned for SEM imaging. The observation from SEM shown in Additional file 1: Fig. S7 provides a qualitative view of the membrane morphology. The images obtained offer an idea of the stability of the PIM and GPM membranes after the extraction step. The almost similar morphology proves that the adopted membranes preserve the same characteristic before and after extraction experiments. Furthermore, concerning the PIM confirms that the relative swelling rate does not seem to influence its morphology.

\section{Conclusion}

This work, conceptualized and quantified the performances and the mechanisms of oriented membrane processes for the facilitated extraction of paracetamol through PIM and GPM.

Two membranes PIM-GA and GPM-GA, were developed following the heat vulcanization and phase inversion methods and characterized by FT-IR and SEM techniques. The optimal identified operating conditions as substrate concentration, acidity, and temperature factors on the evolution of the different parameters were investigated, and the better paracetamol extraction was obtained for $\mathrm{C}_{0}=0.01 \mathrm{~mol} \mathrm{~L}^{-1}$ at $\mathrm{pH}=1$ and $308 \mathrm{~K}$, with $D^{*}\left(10^{-7} \mathrm{~cm}^{2} \mathrm{~s}^{-1}\right)=29.812$ through PIM membrane.

Analysis of obtained results shows a good membrane performance observed even at low temperatures and indicates a kinetic aspect controlled the mechanism of extraction of this biologically active compound (paracetamol) through the two developed membranes. We can conclude that the paracetamol molecules can potentially 
diffuse through the cell walls having well-adapted structures at a constant temperature. Consequently, the kinetic control of the extraction processes of paraceta$\mathrm{mol}$ is an original idea, and the studies produced logical results. It can be correlated to the molecular structures of paracetamol and the extractive agent. After these all studies, we can consider the adopted membranes would be very efficient for extracting and recovering paracetamol from industrial liquid discharges and providing a clean, sustainable, and environmentally friendly method for the extraction and recovery of the paracetamol molecule as a high-value substance.

\begin{abstract}
Abbreviations
$[\mathbf{T}]_{0}$ : Concentration of carrier in the membrane phase $\left(\mathrm{mol} \mathrm{L}^{-1}\right) ; \mathrm{C}_{0}$ : Initial concentration of paracetamol in the feed phase $\left(\mathrm{mol} \mathrm{L}^{-1}\right) ; \mathbf{C}_{\mathbf{R}}$ : Concentration of paracetamol in the receiving phase $\left(\mathrm{mol} \mathrm{L}^{-1}\right) ; \boldsymbol{P}$ : Permeability of the membrane $\left(\mathrm{cm}^{2} \mathrm{~s}^{-1}\right) ; \boldsymbol{J}_{0}$ : Initial flux $\left(\mathrm{mmol} \mathrm{s} \mathrm{cm}^{-2}\right) ; \boldsymbol{D}^{*}$. Apparent diffusion coefficient $\left(\mathrm{cm}^{2} \mathrm{~s}^{-1}\right) ; \boldsymbol{K}_{\text {ass }}$ : Association constant; $\boldsymbol{l}$ : Membrane thickness $(\mu \mathrm{m})$; $\mathbf{t}$ : Time (s); V: Volume of the receiving phase $\left(\mathrm{cm}^{3}\right)$; $\mathbf{S}$ : Active area of the membrane $\left(\mathrm{cm}^{2}\right)$; $\mathbf{T}$ : Temperature $(\mathrm{K})$; $\mathbf{R}$ : Ideal gas constant $\left(\mathrm{J} \mathrm{mol}^{-1} \mathrm{~K}^{-1}\right)$; $\boldsymbol{E}_{\boldsymbol{a}}$ : Activation energy ( $\left.\mathrm{KJ} \mathrm{mol}^{-1}\right) ; \boldsymbol{\Delta} \boldsymbol{H}_{\text {ass }}$ : Activation association enthalpy $\left(\mathrm{KJ} \mathrm{mol}^{-1}\right)$; $\Delta \boldsymbol{H}^{\neq}$diss: Activation dissociation enthalpy $\left(\mathrm{KJ} \mathrm{mol}^{-1}\right) ; \boldsymbol{\Delta} \boldsymbol{S}^{\neq}$: Activation entropy ( $\left.\mathrm{KJ} \mathrm{mol}^{-1} \mathrm{~K}^{-1}\right) ; \boldsymbol{\Delta} \boldsymbol{H}_{t h}$ : Thermodynamic enthalpy $\left(\mathrm{KJ} \mathrm{mol}^{-1}\right)$.
\end{abstract}

\section{Supplementary Information}

The online version contains supplementary material available at https://doi. org/10.1186/s13065-021-00794-7.

Additional file 1: Figure S1. Representation of the facilitated extraction cell. Figure S2. Swelling degree versus time of different membrane samples at $\mathrm{pH}=1,2$ and 3. Figure $\mathbf{S 3}$. Mechanism of successive jumps on semi-mobile and fixed sites during the facilitated extraction process of paracetamol through the PIM-GA and GPM-GA membranes. Figure S4. Possible interaction sites between paracetamol and gluconic acid. Figure S5. Interaction sites between paracetamol and gluconic acid (Chemdrew). Figure S6. The permeability relative to the facilitated extraction processes of paracetamol at $\mathrm{C}_{0}=0.08 \mathrm{M}, \mathrm{pH}=1$ and $\mathrm{T}=298 \mathrm{~K}$, during a period of six months. Figure S7. SEM micrographs after extraction process of $(a, b)$ membrane cross-section (GPM-GA), (c d) membrane surface (PIM-GA).

\section{Acknowledgements}

The authors wish to thank the Ministry of Higher Education and Scientific Research (MESRSFC) and the National Center of Scientific and Technical Research (CNRST) for their financial support PPR2 Project. PPR2 Project: Ministry of Higher Education, Scientific Research and Management TrainingNational Center for Scientific and Technical Research.

\section{Authors' contributions}

ST did most of the experiment and wrote the manuscript. RL and EAEH did the preparation and characterization of the membrane. MH helped in editing the English language beside adding some paragraphs to the text. All authors read and approved the final manuscript.

\section{Funding}

Not applicable.

\section{Availability of data and materials}

The datasets used and/or analyzed during the current study are available from the corresponding author on reasonable request.

\section{Declarations}

Ethics approval and consent to participate

Not applicable.

\section{Consent for publication}

Not applicable.

\section{Competing interests}

All authors declare that they have no competing interest, financial or personal, which may influence the work reported in this paper.

Received: 13 April 2021 Accepted: 28 December 2021

Published online: 13 January 2022

References

1. Ang WL, Mohammad AW, Hilal N, Leo CP. A review on the applicability of integrated/hybrid membrane processes in water treatment and desalination plants. Desalination. 2015;363:2-18. https://doi.org/10.1016/j.desal. 2014.03.008.

2. Boleda MR, Galceran MT, Ventura F. Validation and uncertainty estimation of a multiresidue method for pharmaceuticals in surface and treated waters by liquid chromatography-tandem mass spectrometry. J Chromatogr A. 2013;1286:146-58. https://doi.org/10.1016/j.chroma.2013.02.077.

3. Kümmerer K. The presence of pharmaceuticals in the environment due to human use-present knowledge and future challenges. J Environ Manag. 2009;90:2354-66.

4. Shi X, Leong KY, Ng HY. Anaerobic treatment of pharmaceutical wastewater: a critical review. Bioresour Technol. 2017;245:1238-44. https://doi.org/ 10.1016/j.biortech.2017.08.150.

5. Wang $Y$, Huang $H$, Wei X. Influence of wastewater precoagulation on adsorptive filtration of pharmaceutical and personal care products by carbon nanotube membranes. Chem Eng J. 2018;333:66-75. https://doi. org/10.1016/j.cej.2017.09.149.

6. Comtois-Marotte S, Chappuis T, Vo Duy S, Gilbert N, Lajeunesse A Taktek S, et al. Analysis of emerging contaminants in water and solid samples using high resolution mass spectrometry with a $\mathrm{Q}$ exactive orbital ion trap and estrogenic activity with YES-assay. Chemosphere. 2017;166:400-11.

7. Garcia-Rodríguez A, Fontàs C, Matamoros V, Almeida MIGS, Cattrall RW, Kolev SD. Development of a polymer inclusion membrane-based passive sampler for monitoring of sulfamethoxazole in natural waters. Minimizing the effect of the flow pattern of the aquatic system. Microchem J. 2016:124:175-80.

8. Defarges TM, Guerbet M, Massol J. Impact des médicaments sur l'environnement: état des lieux, évaluation des risques, communication Ther Recreat J. 2011;66:335-40.

9. Galambos I, Molina JM, Jaray P, Vatai G, Bekassy-Molnar E. High organic content industrial wastewater treatment by membrane filtration. Desalination. 2004;162:117-20.

10. Tang Y, Liu W, Wan J, Wang Y, Yang X. Two-stage recovery of S-adenosylmethionine using supported liquid membranes with strip dispersion. Process Biochem. 2013;48:1980-91. https://doi.org/10.1016/j.procbio. 2013.09.006.

11. Zouhri A, Ernst B, Burgard M. Bulk liquid membrane for the recovery of chromium (VI) from a hydrochloric acid medium using dicyclohexano18-crown-6 as extractant-carrier. Sep Sci Technol. 1999:34:1891-905.

12. Kumar S, Babu BV. Separation of carboxylic acids from waste water via reactive extraction. In: International convention on water resources development and management. 2008. http://citeseerx.ist.psu.edu/viewd oc/download?doi=10.1.1.207.1142\&rep=rep1\&type=pdf\%0Ahttp:// discovery.bits-pilani.ac.in/discipline/chemical/bvb/SK_BVB_CarboxAcid_ ICWRDM_2008.pdf.

13. LaPara TM, Nakatsu CH, Pantea LM, Alleman JE. Aerobic biological treatment of a pharmaceutical wastewater: effect of temperature on COD removal and bacterial community development. Water Res. 2001;35:4417-25 
14. Ziylan A, Ince NH. The occurrence and fate of anti-inflammatory and analgesic pharmaceuticals in sewage and fresh water: treatability by conventional and non-conventional processes. J Hazard Mater. 2011;187:24-36. https://doi.org/10.1016/j.jhazmat.2011.01.057.

15. Parolini M. Toxicity of the non-steroidal anti-inflammatory drugs (NSAIDs) acetylsalicylic acid, paracetamol, diclofenac, ibuprofen and naproxen towards freshwater invertebrates: a review. Sci Total Environ. 2020;740: 140043. https://doi.org/10.1016/j.scitotenv.2020.140043.

16. Kosjek T, Heath E, Krbavcic A. Determination of non-steroidal antiinflammatory drug (NSAIDs) residues in water samples. Environ Int. 2005;31:679-85.

17. Andreozzi R, Raffael M, Nicklas P. Pharmaceuticals in STP effluents and their solar photodegradation in aquatic environment. Chemosphere. 2003;50:1319-30.

18. Stumpf M, Ternes TA, Wilken R, Rodrigues SV, Baumann W. Polar drug residues in sewage and natural waters in the state of Rio de Janeiro, Brazil. Sci Total Environ. 1999;225:135-41.

19. Comeau F, Surette C, Brun GL, Losier R. The occurrence of acidic drugs and caffeine in sewage effluents and receiving waters from three coastal watersheds in Atlantic Canada. Sci Total Environ. 2008:396:132-46.

20. Zidi C, Tayeb R, Dhahbi M. Comparaison entre le transport facilité à travers une Membrane à Liquide Supporté (MLS) du phénol et de la vanilline extraits de milieux aqueux (Comparison between facilitated transport through a supported liquid membrane (SLM) of phenol and vanillin extr). J Mater Environ Sci. 2014;5:779-82.

21. Senhadji OK, Sahi S, Kahloul N, Tingry S, BenAmor M, Seta P. Extraction du Cr(VI) par membrane polymere a inclusion. Sci Technol A. 2008;27:43-50.

22. Dzygiel P, Wieczorek PP. Supported liquid membranes and their modifications: definition, classification, theory, stability, application and perspectives. In: Liquid membranes. Amsterdam: Elsevier; 2010. p. 73-140.

23. Strathmann $\mathrm{H}$. Membranes and membrane separation processes, 1. Princ Ullmann's Encycl Ind Chem. 2011. https://doi.org/10.1002/14356007.a16.

24. Charcosset $C$. Procédés membranaires à application pharmaceutique et biotechnologique. ITBM-RBM. 2006;27:1-7. https://doi.org/10.1016/j. rbmret.2005.10.003.

25. Baudot A, Floury J, Smorenburg HE. Liquid-liquid extraction of aroma compounds with hollow fiber contactor. AIChE J. 2001:47:1780-93.

26. Liu X, Ma Y, Cao T, Tan D, Wei X, Yang J, et al. Enantioselective liquid-liquid extraction of amino acid enantiomers using (S)-MeO-BIPHEP-metal complexes as chiral extractants. Sep Purif Technol. 2019;211:189-97. https:// doi.org/10.1016/j.seppur.2018.09.068.

27. Shintani H. Liquid-liquid extraction vs solid phase extraction in biological fluids and drugs. Int J Clin Pharmacol Toxicol. 2013. https://doi.org/10. 19070/2167-910X-130004e.

28. Eljaddi T, Lebrun L, Hlaibi M. Review on mechanism of facilitated transport on liquid membranes. J Membr Sci Res. 2017;3:199-208.

29. Jean E, Villemin D, Hlaibi M, Lebrun L. Heavy metal ions extraction using new supported liquid membranes containing ionic liquid as carrier. Sep Purif Technol. 2018;201:1-9. https://doi.org/10.1016/.jseppur.2018.02.033.

30. Xie R, Chu L-Y, Deng J-G. Membranes and membrane processes for chiral resolution. Chem Soc Rev. 2008;37:1243-63.

31. Ershad M, Almeida MIGS, Spassov TG, Cattrall RW, Kolev SD. Polymer inclusion membranes (PIMs) containing purified dinonylnaphthalene sulfonic acid (DNNS): performance and selectivity. Sep Purif Technol. 2018;195:446-52. https://doi.org/10.1016/j.seppur.2017.12.037.

32. Galiano F, Briceño K, Marino T, Molino A, Christensen KV, Figoli A. Advances in biopolymer-based membrane preparation and applications. J Membr Sci. 2018;564:562-86. https://doi.org/10.1016/j.memsci.2018.07. 059.

33. O'Rourke M, Cattrall RW, Kolev SD, Potter ID. The extraction and transport of organic molecules using polymer inclusion membranes. Solvent Extr Res Dev. 2009;16:1-12.

34. Nghiem LD, Mornane P, Potter ID, Perera JM, Cattrall RW, Kolev SD. Extraction and transport of metal ions and small organic compounds using polymer inclusion membranes (PIMs). J Membr Sci. 2006;281:7-41.

35. Fontas C, Tayeb R, Dhahbi M, Gaudichet E, Thominette F, Roy P, et al. Polymer inclusion membranes: the concept of fixed sites membrane revised. J Membr Sci. 2007;290:62-72.

36. Zaidi SMJ, Mauritz KA, Hassan MK. Membrane surface modification and functionalization. Functional Polymers. 2018;1-26.
37. Mouadili H, Majid S, Kamal O, Elatmani ELH, Touaj K, Lebrun L, et al. New grafted polymer membrane for extraction, separation and recovery processes of sucrose, glucose and fructose from the sugar industry discharges. Sep Purif Technol. 2018;200:230-41. https://doi.org/10.1016/j. seppur.2017.12.012.

38. Haponska M, Trojanowska A, Nogalska A, Jastrzab R, Gumi T, Tylkowski B. PVDF membrane morphology-influence of polymer molecular weight and preparation temperature. Polymers. 2017;9:718. https://doi.org/10. 3390/polym9120718.

39. Kang GD, Cao YM. Application and modification of poly(vinylidene fluoride) (PVDF) membranes_a review. J Membr Sci. 2014;463:145-65. https://doi.org/10.1016/j.memsci.2014.03.055.

40. El Atmani EH, Benelyamani A, Mouadili H, Tarhouchi S, Majid S, Touaj K, et al. The oriented processes for extraction and recovery of paracetamol compound across different affinity polymer membranes. Parameters and mechanisms. Eur J Pharm Biopharm. 2018;126:201-10. https://doi.org/10. 1016/j.jpb.2017.06.001.

41. Jiang S, Ladewig BP. Green synthesis of polymeric membranes: recent advances and future prospects. Curr Opin Green Sustain Chem. 2019. https://doi.org/10.1016/..cogsc.2019.07.002.

42. Rafiq S, Deng L, Hägg MB. Role of facilitated transport membranes and composite membranes for efficient $\mathrm{CO} 2$ capture - a review. ChemBioEng Rev. 2016;3:68-85.

43. Deng L, Kim TJ, Hägg MB. Facilitated transport of $\mathrm{CO} 2$ in novel PVAm/PVA blend membrane. J Membr Sci. 2009:340:154-63.

44. Louafy R, Benelyamani A, Tarhouchi S, Kamal O, Touaj K, Hlaibi M. Parameters and mechanism of membrane-oriented processes for the facilitated extraction and recovery of norfloxacin active compound. Environ Sci Pollut Res. 2020;27:37572-80. https://doi.org/10.1007/s11356-020-09311-0.

45. Heydari M, Moheb A, Ghiaci M, Masoomi M. Effect of cross-linking time on the thermal and mechanical properties and pervaporation performance of poly(vinyl alcohol) membrane cross-linked with fumaric acid used for dehydration of isopropanol. J Appl Polym Sci. 2013;128:1640-51.

46. Işiklan N, Şanli O. Separation characteristics of acetic acid-water mixtures by pervaporation using poly(vinyl alcohol) membranes modified with malic acid. Chem Eng Process. 2005;44:1019-27.

47. Korsmeyer RWPN. Effect of the morphology of hydrophilic polymeric. J Membr Sci. 1981;9:211-27.

48. Giménez V, Mantecon A, Ronda JCCV. Poly (vinyl alcohol) modified with carboxylic acid anhydrides: crosslinking through carboxylic groups. J Appl Polym Sci. 1997;65:1643-51.

49. Mallapragada SKPN. Dissolution mechanism of semicrystalline poly (viny1 alcohol) in water. J Polym Sci B Polym Phys. 1996;34:1339-46.

50. Hassan CM, Peppas NA. Structure and applications of poly (vinyl alcohol) hydrogels produced by conventional crosslinking or by freezing/thawing methods. Adv Polym Sci. 2000;153:37-65.

51. Peh KK, Wong CF. Polymeric films as vehicle for buccal delivery: swelling, mechanical, and bioadhesive properties. J Pharm Pharm Sci. 1999;2:53-61.

52. Fumio U, Hiroshi Y, Kumiko N, Sachihiko N, Kenji S, Yasunori M. Swelling and mechanical properties poly (vinyl alcohol) hydrogels. Int J Pharm. 1990;58:135-42.

53. Turković E, Vasiljević I, Drašković M, Obradović N, Vasiljević D, Parojčić J. An investigation into mechanical properties and printability of potential substrates for inkjet printing of orodispersible films. Pharmaceutics. 2021;13:468.

54. Brant AJC, Giannini DR, Pessoa JOCP, Andrade AB. Influence of dissolution processing of PVA blends on the characteristics of their hydrogels synthesized by radiation —Part I: gel fraction, swelling, and mechanical properties. Radiat Phys Chem. 2012:81:1465-70.

55. Gupta B, Büchi FN, Scherer GG, Chapiró A. Crosslinked ion exchange membranes by radiation grafting of styrene/divinylbenzene into FEP films. J Membr Sci. 1996;118:231-8.

56. Hassoune $\mathrm{H}$, Rhlalou T, Verchère JF. Mechanism of transport of sugars across a supported liquid membrane using methyl cholate as mobile carrier. Desalination. 2009;242:84-95. https://doi.org/10.1016/j.desal.2008. 03.033.

57. Kamal O, Eljaddi T, El Atmani EH, Touarssi I, Mourtah I, Lebrun L, et al. Process of facilitated extraction of vanadium ions through supported liquid membranes: parameters and mechanism. Adv Mater Sci Eng. 2017. https://doi.org/10.1155/2017/3425419. 
58. Eljaddi T, Hor M, Benjjar A, Riri M, Mouadili H, Mountassir Y, et al. New supported liquid membrane for studying facilitated transport of $U(\mathrm{VI})$ ions using tributyl phosphate (TBP) and Tri-n-octylamine (TOA) as carriers from acid medium. BAOJ Chem. 2015;1:1-9.

59. Touaj K, Tbeur N, Hor M. A supported liquid membrane (SLM) with resorcinarene for facilitated transport of methyl glycopyranosides: parameters and mechanism relating to the transport. J Membr Sci. 2009;337:28-38.

60. Chaouqi Y, Ouchn R, Tarik E, Amane J, Elbouchti M, Cherkaoui O. Oriented processes for extraction and recovery of blue P3R dye across hybrid polymer membranes: parameters and mechanism. J Membr Sci Res. 2019;5:303-9.

61. Touarssi I, Mourtah I, Chaouqi Y, Kamal O, Sefiani N, Lebrun L, et al. Conceptualization and quantification of oriented membrane processes for recovering vanadium ions from acidic industrial discharges. J Environ Chem Eng. 2019;7: 103182.

62. Chaouqi Y, Ouchn R, Touarssi I, Mourtah I, El Bouchti M, Lebrun L, et al. Polymer inclusion membranes for selective extraction and recovery of hexavalent chromium ions from mixtures containing industrial blue P3R dye. Ind Eng Chem Res. 2019;58:18798-809.

63. Eyring $\mathrm{H}$. The activated complex in chemical reactions. J Chem Phys. 1935;3:107-15.

64. Lazarova Z, Boyadzhiev L. Kinetic aspects of copper (II) transport across liquid membrane containing LIX-860 as a carrier. J Membr Sci. 1993;78:239-45.

65. Benjjar A, Hor M, Riri M, Eljaddi T, Kamal O, Lebrun L, et al. A new supported liquid membrane (SLM) with methyl cholate for facilitated transport of dichromate ions from mineral acids: parameters and mechanism relating to the transport. J Mater Environ Sci. 2012;3:826-39.

66. Ohashi H, Ebina S, Yamaguchi T. Logistic gate-like permeable property of gating membrane with ion-recognition polyampholyte. Polymer. 2014:55:1412-9. https://doi.org/10.1016/j.polymer.2013.11.048.

67. Ma P, Chen XD, Hossain MM. Lithium extraction from a multicomponent mixture using supported liquid membranes. Sep Sci Technol. 2000;35:2513-33.

68. Tbeur N, Rhlalou T, Hlaíbi M, Langevin D, Métayer M, Verchère JF. Molecular recognition of carbohydrates by a resorcinarene. Selective transport of alditols through a supported liquid membrane. Carbohydr Res. 2000;329:409-22.

69. Hlaïbi M, Tbeur N, Benjjar A, Kamal O, Lebrun L. Carbohydrate-resorcinarene complexes involved in the facilitated transport of alditols across a supported liquid membrane. J Membr Sci. 2011;377:231-40.

70. Kamal O, Eljaddi T, Atmani EHEL, Touarssi I, Lebrun L, Hlaïbi M. Grafted polymer membranes with extractive agents for the extraction process of VO2+ ions. Polym Adv Technol. 2017;28:541-8.

71. Li Y, Wang S, He G, Wu H, Jiang Z. Facilitated transport of small molecules and ions for energy-efficient membranes. Chem Soc Rev. 2014;44:103-18. https://doi.org/10.1039/C4CS00215F.

72. Anticó E, Vera R, Vázquez F, Fontàs C, Lu C, Ros J. Preparation and characterization of nanoparticle-doped polymer inclusion membranes: application to the removal of arsenate and phosphate from waters. Materials. 2021;14:1-15

73. Vera R, Fontàs C, Galceran J, Serra O, Anticó E. Polymer inclusion membrane to access Zn speciation: comparison with root uptake. Sci Total Environ. 2018;622-623:316-24. https://doi.org/10.1016/j.scitotenv.2017. 11.316

\section{Publisher's Note}

Springer Nature remains neutral with regard to jurisdictional claims in published maps and institutional affiliations.
Ready to submit your research? Choose BMC and benefit from:

- fast, convenient online submission

- thorough peer review by experienced researchers in your field

- rapid publication on acceptance

- support for research data, including large and complex data types

- gold Open Access which fosters wider collaboration and increased citations

- maximum visibility for your research: over $100 \mathrm{M}$ website views per year

At BMC, research is always in progress.

Learn more biomedcentral.com/submissions 